\title{
Dynamics of Zika virus outbreaks: an overview of mathematical modeling approaches
}

\author{
Anuwat Wiratsudakul ${ }^{1,2}$, Parinya Suparit ${ }^{3}$, Charin Modchang ${ }^{\text {Corresp. } 3,4}$ \\ ${ }^{1}$ Department of Clinical Sciences and Public Health, Faculty of Veterinary Science, Mahidol University, Phutthamonthon, Nakhon Pathom, Thailand \\ 2 The Monitoring and Surveillance Center for Zoonotic Diseases in Wildlife and Exotic Animals, Faculty of Veterinary Science, Mahidol University, \\ Phutthamonthon, Nakhon Pathom, Thailand \\ 3 Biophysics Group, Department of Physics, Faculty of Science, Mahidol University, Ratchathewi, Bangkok, Thailand \\ 4 Centre of Excellence in Mathematics, CHE, Ratchathewi, Bangkok, Thailand
}

Corresponding Author: Charin Modchang

Email address: charin.mod@mahidol.edu

Background. The Zika virus was first discovered in 1947. It was neglected until a major outbreak occurred on Yap Island, Micronesia, in 2007. Teratogenic effects resulting in microcephaly in newborn infants is the greatest public health threat. In 2016, the Zika virus epidemic was declared as a Public Health Emergency of International Concern (PHEIC). Consequently, mathematical models were constructed to explicitly elucidate related transmission dynamics.

Survey Methodology. In this review article, two steps of journal article searching were performed. First, we attempted to identify mathematical models previously applied to the study of vector-borne diseases using the search terms "dynamics," "mathematical model," "modeling," and "vector-borne" together with the names of vector-borne diseases including chikungunya, dengue, malaria, West Nile, and Zika. Then the identified types of model were further investigated. Second, we narrowed down our survey to focus on only Zika virus research. The terms we searched for were "compartmental," "spatial," "metapopulation," "network," "individual-based," "agent-based" AND "Zika." All relevant studies were included regardless of the year of publication. We have collected research articles that were published before August 2017 based on our search criteria. In this publication survey, we explored the Google Scholar and PubMed databases.

Results. We found five basic model architectures previously applied to vector-borne virus studies, particularly in Zika virus simulations. These include compartmental, spatial, metapopulation, network, and individual-based models. We found that Zika models carried out for early epidemics were mostly fit into compartmental structures and were less complicated compared to the more recent ones. Simple models are still commonly used for the timely assessment of epidemics. Nevertheless, due to the availability of large-scale real-world data and computational power, recently there has been growing interest in more complex modeling frameworks.

Discussion. Mathematical models are employed to explore and predict how an infectious disease spreads in the real world, evaluate the disease importation risk, and assess the effectiveness of intervention strategies. As the trends in modeling of infectious diseases have been shifting towards datadriven approaches, simple and complex models should be exploited differently. Simple models can be produced in a timely fashion to provide an estimation of the possible impacts. In contrast, complex models integrating real-world data require more time to develop but are far more realistic. The preparation of complicated modeling frameworks prior to the outbreaks is recommended including the case of future Zika epidemic preparation. 


\section{Dynamics of Zika virus outbreaks: an overview of}

\section{2 mathematical modeling approaches}

3

4 Anuwat Wiratsudakul ${ }^{1,2}$, Parinya Suparit ${ }^{3}$, and Charin Modchang ${ }^{3,4}$

$5 \quad{ }^{1}$ Department of Clinical Sciences and Public Health, Faculty of Veterinary Science, Mahidol

6 University, Phutthamonthon, Nakhon Pathom 73170, Thailand

$7 \quad{ }^{2}$ The Monitoring and Surveillance Center for Zoonotic Diseases in Wildlife and Exotic Animals,

8 Faculty of Veterinary Science, Mahidol University, Phutthamonthon, Nakhon Pathom 73170,

9 Thailand

10 B3iophysics Group, Department of Physics, Faculty of Science, Mahidol University, Bangkok

11 10400, Thailand

$12{ }^{4}$ Centre of Excellence in Mathematics, CHE, Bangkok 10400, Thailand

13

14 Corresponding Author

15 Charin Modchang

16 Email: charin.mod@mahidol.edu

17

18

19

20

21 


\section{Abstract}

Background. The Zika virus was first discovered in 1947. It was neglected until a major outbreak occurred on Yap Island, Micronesia, in 2007. Teratogenic effects resulting in microcephaly in newborn infants is the greatest public health threat. In 2016, the Zika virus epidemic was declared as a Public Health Emergency of International Concern (PHEIC). Consequently, mathematical models were constructed to explicitly elucidate related transmission dynamics.

Survey Methodology. In this review article, two steps of journal article searching were performed. First, we attempted to identify mathematical models previously applied to the study of vectorborne diseases using the search terms "dynamics," "mathematical model," "modeling," and "vector-borne" together with the names of vector-borne diseases including chikungunya, dengue, malaria, West Nile, and Zika. Then the identified types of model were further investigated. Second, we narrowed down our survey to focus on only Zika virus research. The terms we searched for were “compartmental," “spatial,” “metapopulation,” “network," “individual-based,” “agentbased” AND “Zika." All relevant studies were included regardless of the year of publication. We have collected research articles that were published before August 2017 based on our search criteria. In this publication survey, we explored the Google Scholar and PubMed databases.

Results. We found five basic model architectures previously applied to vector-borne virus studies, particularly in Zika virus simulations. These include compartmental, spatial, metapopulation, network, and individual-based models. We found that Zika models carried out for early epidemics

44 were mostly fit into compartmental structures and were less complicated compared to the more 45 recent ones. Simple models are still commonly used for the timely assessment of epidemics. 
46 Nevertheless, due to the availability of large-scale real-world data and computational power,

47 recently there has been growing interest in more complex modeling frameworks.

48 Discussion. Mathematical models are employed to explore and predict how an infectious disease

49 spreads in the real world, evaluate the disease importation risk, and assess the effectiveness of intervention strategies. As the trends in modeling of infectious diseases have been shifting towards data-driven approaches, simple and complex models should be exploited differently. Simple models can be produced in a timely fashion to provide an estimation of the possible impacts. In contrast, complex models integrating real-world data require more time to develop but are far more realistic. The preparation of complicated modeling frameworks prior to the outbreaks is recommended including the case of future Zika epidemic preparation.

\section{Introduction}

Zika is a single-stranded RNA flavivirus, a member of the Flaviviridae family (Lopes et al., 2016). The virus is genetically related to some others responsible for encephalitis in humans, including chikungunya, dengue, Japanese encephalitis, West Nile, and the yellow fever virus

61 (Lucey \& Gostin, 2016; Goeijenbier et al., 2016; Vest, 2016). Zika is one of the arboviruses transmitted by Aedes mosquitoes. The main vectors are Aedes aegypti and Aedes albopictus (AlQahtani et al., 2016). These mosquitoes are mostly found in tropical and subtropical regions 64 (Petersen et al., 2016).

The Zika virus was first discovered in rhesus monkeys in 1947 while researchers were studying yellow fever in Zika Forest, Uganda, and it was isolated from Aedes africanus mosquitoes

67 the subsequent year (Dick, Kitchen, \& Haddow, 1952). The first human isolation was recorded in 68 Nigeria six years later (MacNamara, 1954; Petersen et al., 2016). For decades, the viral infection 
69 was sporadically reported in Africa and Southeast Asia (Hayes, 2009; Goeijenbier et al., 2016).

70 The first large outbreaks occurred on Yap Island, Federated States of Micronesia, in 2007 (Duffy

71 et al., 2009). In this epidemic, 49 confirmed cases were found together with another 59 probable

72 cases. It was estimated that up to $73 \%$ of the Yap Island residents were asymptomatically infected

73 (Duffy et al., 2009; Kindhauser et al., 2016). The episodes of large-scale Zika virus outbreaks

74 happened in 2013, when the virus migrated to French Polynesia, a French territory located in the

75 South Pacific. This outbreak was the largest recorded at the time (Cao-Lormeau et al., 2014, 2016;

76 Musso, 2015). Overall, 19,000 suspected cases were estimated throughout the epidemic's course

77 (Cao-Lormeau et al., 2014). The first evidence of Guillain-Barré syndrome related to the Zika

78 virus was also seen in this historic outbreak (Cao-Lormeau et al., 2016). Subsequently, the virus

79 from French Polynesia dispersed to many countries in the Pacific Ocean, finally reaching Easter

80 Island, Chile, in 2014 (Tognarelli et al., 2015). The virus seems to have established well on the

81 continent, especially in Latin American countries (Shi et al., 2016). For example, the

82 autochthonous transmission was first confirmed in Brazil in 2015 (Zanluca et al., 2015) and the

83 Brazilian Ministry of Health estimated the number of suspected cases at 440,000 to 1,300,000 that

84 year. The Zika infection was also linked to the unusual rising incidence of microcephaly in

85 newborn infants (Mlakar et al., 2016; de Oliveira \& da Costa Vasconcelos, 2016; Heymann et al.,

86 2016) together with some other neurological disorders including Guillain-Barré syndrome (de

87 Oliveira et al., 2017). On February 1, 2016, the World Health Organization (WHO) Director-

88 General declared Zika virus outbreaks in Latin American countries as a Public Health Emergency

89 of International Concern (PHEIC) (Heymann et al., 2016). As of March 9, 2017, vector-borne Zika

90 virus transmission was found in 84 countries, territories, or subnational areas (WHO, 2017). 
92 diseases threaten the human race. With rapid globalization, these diseases are often disseminated

93 at unprecedented speed. The epidemics of severe acute respiratory syndrome (SARS) in 2003 and

94 the H1N1 influenza pandemic of 2009 are excellent evidence in the first decade (Mackey \& Liang,

95 2012). More recently, we face new threats almost every year, for example, the Middle East

96 respiratory syndrome coronavirus (MERS-CoV) in Saudi Arabia in 2012 (de Groot et al., 2013),

97 the Ebola virus in the West African region in 2014 (WHO Ebola Response Team, 2014). In such

98 epidemics, the real-time evaluation of the ongoing situation is vitally important. To serve this

99 purpose, mathematical modeling has been exploited to monitor the outbreak progression, predict

100 the trend of disease transmission, and tailor related control strategies (McVernon, McCaw, \&

101 Mathews, 2007; de Jong \& Hagenaars, 2009).

102 Infectious disease modeling is an interdisciplinary approach. Modelers are obligated to

103 comprehend not only the mathematical frameworks but also the biological knowledge behind the

104 epidemics (Rock et al., 2014b). Recently, mathematical modeling has been well established as an

105 epidemiological tool. It has been used to combat many infectious diseases. The very first

106 mathematical model was traced back to the work of Daniel Bernoulli in the eighteenth century.

107 Bernoulli employed a simple model to estimate life expectancy due to variolation practices in

108 smallpox epidemics (Bernoulli, 1766). However, the modern era of infectious disease modeling

109 was actually initiated a century ago with a mosquito-borne model proposed by Sir Ronald Ross.

110 Ross developed a set of mathematical equations to illustrate how malaria parasites were

111 transmitted between mosquitoes and humans (Ross, 1911). The model was later complemented by

112 the work of Macdonald (MacDonald, 1952), and finally became the well-known Ross-Macdonald

113 models. This modeling framework still plays an important role in research on malaria and other 
114 mosquito-borne diseases (Smith et al., 2012). Nevertheless, there were also many other scientists

115 working on malaria transmission dynamics. For instance, Kermack and McKendrick incorporated

116 the law of mass action into the Ross model and proposed new and modern compartmental models

117 (Kermack \& McKendrick, 1927, 1932, 1933) that later became the most widely used basic

118 structures in infectious disease modeling.

119 The present review aims to provide an overview of mathematical modeling methods,

120 particularly those developed for Zika virus transmission. However, it is not possible to cover, in

121 a review, all kinds of mathematical models applied to infectious disease studies. In this review, we

122 describe some common models developed thus far. We explain different approaches ranging from

123 simple compartments to sophisticated models integrating real-word data. The idea is to provide

124 some basic knowledge of mathematical projections before further exploring the models,

125 particularly those developed for Zika virus transmission. We also discuss recent advances and

126 trends of research in the infectious disease modeling.

\section{Survey Methodology}

We attempt to cover different types of mathematical models applied to the study of vector-

130 borne disease, particularly the Zika virus. First, we provide basic knowledge on methodological

131 approaches in order to facilitate non-mathematical background readers. We therefore initiated our

132 survey to investigate previously published modeling frameworks. Subsequently, we further

133 explore specifically the use of models in the study of the Zika virus. In our publication survey, we

134 used the Google Scholar (https://scholar.google.com/) and PubMed

135 (http://www.ncbi.nlm.nih.gov/pubmed/) databases to search for the relevant peer-reviewed journal 136 articles. In the first step, we used the search terms "dynamics," "mathematical model," 
137 "modeling," and "vector-borne" together with the names of vector-borne diseases including

138 chikungunya, dengue, malaria, West Nile, and Zika. Then, we expanded our search to include the

139 related models identified by the prior screening. The secondary search terminologies included

140 “compartmental," "spatial," "metapopulation," "network," "individual-based," and "agent-based."

141 In the second step, we examined only the models applied to Zika virus simulations. We strictly

142 searched for publications focusing on the applications of mathematical modeling in Zika virus

143 research. The search terms were then designated as the names of the modeling techniques

144 described earlier AND “Zika." We consistently excluded unrelated studies throughout the review

145 process. For the publications that met our criteria, we intensively reviewed their modeling

146 methods, categorized into the modeling types and compared to other related studies we found. The

147 papers with irrelevant methodology were then removed.

148 As we tried to capture all available studies, the publication year was unrestricted. However,

149 the mathematical modeling approach in the Zika virus study has recently emerged. Hence, most of

150 the research was recently published. We have collected research articles that were published before

151 August 2017 based on our search criteria.

152

153 Results

154 We found five basic model architectures previously applied to vector-borne research.

155 These include compartmental, spatial, metapopulation, network, and individual-based models. We 156 reviewed these accordingly.

157

158 Basic compartmental model 
160 according to individual health status (Hethcote, 2000). For example, in the SIR model, the

161 population is split into the compartments of susceptible ( $\mathrm{S}$, healthy individuals), infectious (I,

162 diseased and contagious individuals), and recovered ( $\mathrm{R}$, immune individuals). During the course

163 of disease transmission, each individual may progress across the compartments, with the rate

164 illustrated by these ordinary differential equations (Figure 1A):

165

166

$$
\frac{d S}{d t}=-\frac{\beta S I}{N},
$$$$
\frac{d I}{d t}=\frac{\beta S I}{N}-\gamma I, \text { and }
$$

$$
\frac{d R}{d t}=\gamma I
$$

where $\beta$ denotes the transmission rate, dictating the speed at which susceptible individuals become infectious, and $\gamma$ represents the recovery rate, which defines how fast the infectious individuals recovered from the disease. The force of infection in this case is defined as $\beta I / N$, where $N$ is the total population. In this simplest case, it is assumed that the dynamics of disease transmission are much faster than the dynamics of demographic processes, for example, births, deaths, and migration; hence, these demographic dynamics can be ignored. In addition to SIR, other forms of compartmental models exist, for instance, SI, SIS, SIRS, SEIR, SEIRS, MSIR, MSEIR, and MSEIRS, among others. E and $\mathrm{M}$ are acronyms for exposed (individuals already exposed to the disease but not yet infectious) and maternal (those with maternal immunity), respectively. The

177 inclusion of different compartments is based on the nature of the diseases (Hethcote, 2000). The

178 models have been applied to many emerging infectious diseases, for example, avian influenza (de

179 Jong \& Hagenaars, 2009), Ebola (Browne, Gulbudak, \& Webb, 2015; Khan et al., 2015;

180 Santermans et al., 2016; Asher, 2017), HIV/AIDS (Akpa \& Oyejola, 2010; Luo et al., 2015), and 181 many others. 
183 is the basic reproduction number $R_{0}$. The $R_{0}$ is defined as "the average number of secondary cases

184 produced by a single infectious individual in a totally susceptible population in the initial stage of

185 the outbreak" (Hethcote, 2000; Rock et al., 2014b). The $R_{0}$ is regarded as a threshold at which the

186 epidemic is still progressing. The infection may persist and the transmission continues if the $R_{0}$ is

187 greater than 1 , whereas the epidemic is going to cease in the long term when the $R_{0}$ is otherwise

188 (Hethcote, 2000; Rock et al., 2014b; Sidiki \& Tchuente, 2014). This parameter is estimated by

$189 \beta / \gamma$ in the SIR framework (Rock et al., 2014b). Nonetheless, the $R_{0}$ varies considerably from

190 disease to disease. For example, the approximate $R_{0}$ for measles, mumps, and polio is 16,12 , and

1915 , respectively (Glomski \& Ohanian, 2012). Furthermore, the $R_{0}$ values are also different in the

192 same disease but at a different place and time. For example, during the 2014-2015 Ebola virus

193 outbreaks, the $R_{0}$ values were 1.71 for Guinea, 1.83 for Liberia, and 2.02 for Sierra Leone (WHO

194 Ebola Response Team, 2014). Therefore, the $R_{0}$ is not likely referable across spatiotemporal 195 entities.

197 Vector-borne compartmental model

198 The models applied for vector-borne diseases are still globally based on the standard

199 compartmental model. Nonetheless, the compartments designed to visualize the dynamics of 200 vector populations are always incorporated. Indeed, the vector-borne model accounts for a multi201 species approach involving interspecies disease transmission. Hosts and vectors must be present; 202 otherwise, the pathogen cannot spread. The most notable model may refer to the Ross-Macdonald 203 models (Ross, 1911; MacDonald, 1952) for the transmission of malaria. However, the vector204 borne models are often represented in the SEIR and SEI frameworks for human and vector 
205 compartments, respectively (Figure 1B). Here, we demonstrate a model developed to illustrate 206 Zika virus transmission (Funk et al., 2016):

207

$$
\text { Hosts } \quad \begin{aligned}
\frac{d S_{H}}{d t} & =-\lambda_{H} S_{H}, \\
\frac{d E_{H}}{d t} & =\lambda_{H} S_{H}-\delta_{H} E_{H}, \\
\frac{d I_{H}}{d t} & =\delta_{H} E_{H}-\gamma_{H} I_{H}, \\
\frac{d R_{H}}{d t} & =\gamma_{H} I_{H},
\end{aligned}
$$

211 Mosquitoes $\frac{d S_{M}}{d t}=\vartheta_{M}-\lambda_{M} S_{M}-\mu_{M} S_{M}$,

$$
\frac{d E_{M}}{d t}=\lambda_{M} S_{M}-\left(\delta_{M}+\mu_{M}\right) E_{M}, \text { and }
$$

$$
\frac{d I_{M}}{d t}=\delta_{M} E_{M}-\mu_{M} I_{M}
$$

where the subscripts $H$ and $M$ stand for the host and mosquito, respectively. The parameters $\lambda, \delta, \vartheta$, and $\mu$ represent the force of infection, incubation rate, birth rate, and death rate, respectively. The

216 forces of infection for humans and mosquitoes were calculated as:

$$
\lambda_{H}=a p_{H} m I_{M} \text { and }
$$

where $a$ is the mosquito biting rate, $p_{H}$ is the probability that a bite from an infectious mosquito will lead to infection in human, $p_{M}$ is the probability of a mosquito being infected from biting an infectious human, $N_{H}$ is the number of human individuals, and $m$ represents the number of mosquitoes contacting one human.

To get a better understanding of the range of dynamics in these vector-borne diseases, we

224 calculate the number of secondary human cases generated from an average human case, 225 incorporating the cycle of transmission through the vector. To do so, we start with one freshly 
226 infected human. From this primary human case, the expected number of infected mosquitoes is the

227 product of the infectious duration in humans, the rate of disease transmission, and the probability

228 that a newly infected mosquito will progress to the infectious stage: $\left(\frac{1}{\gamma_{H}}\right) \lambda_{M}\left(\frac{\delta_{M}}{\delta_{M}+\mu_{M}}\right)$. Similarly, the

229 expected number of human individuals infected by an infectious mosquito is calculated as $\left(\frac{1}{\mu_{M}}\right) \lambda_{H}$

$230 N_{H}$. Thus, the $R_{0}$ is given by the product of these two terms (Rock et al., 2014a)

231

$$
R_{0}=\left(\frac{1}{\gamma_{H}}\right) \lambda_{M}\left(\frac{\delta_{M}}{\delta_{M}+\mu_{M}}\right)\left(\frac{1}{\mu_{M}}\right) \lambda_{H} N_{H}=\frac{a^{2} p_{M} p_{H} m \delta_{M}}{\gamma_{H} \mu_{M}\left(\delta_{M}+\mu_{M}\right)} .
$$

232 It is noteworthy that this value of $R_{0}$ that includes a complete cycle of transmission is the square

233 of the value calculated using the next-generation matrix approach (Diekmann, Heesterbeek, \&

234 Roberts, 2010); however, they agree on the invasion threshold.

235 Like direct-contact diseases, the $R_{0}$ for vector-borne epidemics varies across space-time 236 settings. For example, the $R_{0}$ for the dengue virus in Brazil ranged from 2-103 in different 237 epidemics in the country from 1996-2003 (Tabachnick, 2016). For Zika, the $R_{0}$ in the outbreaks 238 on Yap Island was estimated between 4.3 and 5.8 in 2007, whereas the value was found at 1.8-2.0 239 in the French Polynesian epidemics in 2013-2014 (Nishiura et al., 2016a). In the recent Zika virus 240 epidemic in Columbia in 2015-2016, the $R_{0}$ was approximately 2.2-14.8 (Nishiura et al., 2016b).

\section{Spatial epidemic model}

According to the first law of geography proposed by Waldo Tobler, "everything is related to everything else, but near things are more related than distant things" (Tobler, 1970). This idea

245 has become a fundamental concept of spatial studies. Spatial epidemiology is a field concerning 246 the geographical distributions of disease incidences (Lawson, 2013). The most primitive tool is 247 disease mapping. However, spatial modeling is much more advanced. This method incorporates 
248 the spatial features of disease occurrences and disease transmission behaviors. In many cases,

249 diseases were observed to spread around the index case. One of the best examples is the airborne

250 virus foot-and-mouth disease (FMD). The FMD virus is capable of transmission by air up to 60

$251 \mathrm{~km}$ on land and up to $250 \mathrm{~km}$ above water bodies (Lee et al., 2013). In addition, spatial cluster

252 causes closer places to become more vulnerable (Lessler et al., 2016). To calculate the spatial

253 probability, the transmission kernel is calculated. The transmission kernel is defined as the

254 probability distribution of distances between the infectious premise and other related places

255 (Lessler et al., 2016). The estimation of this parameter can be performed using various forms, for

256 example, exponential (E), Gaussian (G), and fat-tailed (F) methods, which are demonstrated as

257

258

259

260

261

262

263

264

265

266

267

268

269

270

$$
\begin{aligned}
& K_{E}(x)=\alpha e^{-\alpha x}, \\
& K_{G}(x)=\frac{\alpha}{\sqrt{\pi}} e^{-\alpha^{2} x^{2}}, \text { and } \\
& K_{F}(x)=\frac{\alpha}{4} e^{-\alpha^{1 / 2} x^{1 / 2}},
\end{aligned}
$$

where $\alpha$ denotes the kernel parameter (Szmaragd et al., 2009).

The spatial epidemic models have also been applied to vector-borne diseases. For instance, in the studies of dengue (Delmelle et al., 2016; Sardar \& Saha, 2017; Vincenti-Gonzalez et al., 2017), West Nile (Crowder et al., 2013; Harrigan et al., 2014; Lin \& Zhu, 2017), and Zika (Fitzgibbon, Morgan, \& Webb, 2017), different modeling approaches were used. In the study of the dengue virus, a power-law form time-dependent transmission kernel (Sardar \& Saha, 2017), hot-spot detection and risk factor analysis (Vincenti-Gonzalez et al., 2017), and geographically weighted regression model (Delmelle et al., 2016) were used to illustrate how the virus spreads. In the West Nile virus study, a weighted ensemble model (Harrigan et al., 2014) and a spatially explicit model incorporating land-use and climate variables (Crowder et al., 2013) as well as a reaction-diffusion model using a spatial-temporal risk index (Lin \& Zhu, 2017) were constructed 
271 to explain the spatial diffusion of the virus under different circumstances. For Zika, spatially

272 dependent differential equations were employed to describe the 2015-2016 Zika outbreak in Rio

273 de Janeiro Municipality in Brazil. (Fitzgibbon, Morgan, \& Webb, 2017). A location-specific

274 projection was also performed to estimate the magnitude of Zika virus infections in childbearing

275 women on the American continent (Perkins et al., 2016).

276

277

\section{Metapopulation model}

278

The term “metapopulation” was coined by Richard Levins in 1969 (Levins, 1969) to

279

280

281

282

283

284

285

286

287

288

289

290

291

292 $\frac{d S_{i}}{d t}=-\lambda_{i} S_{i}$

$\frac{d I_{i}}{d t}=\lambda_{i} S_{i}-\gamma I_{i}$, and 


$$
\frac{d R_{i}}{d t}=\gamma I_{i}
$$

294 where the subscript $i$ indicates the parameters and variables that are particular to patch $i$. The force

295 of infection, $\lambda_{i}$, incorporates transmission from both the infectious individuals within patch $i$ and

296 the infectious individuals from patch $j$. The exact formula of $\lambda_{i}$ depends on the assumed mechanism

297 of transmission and the strength of the interaction between the patches. In general, the force of

298 infection is expressed as (Rock et al., 2014a; Sornbundit, Triampo, \& Modchang, 2017)

$$
\lambda_{i}=\sum_{j=1}^{n} \beta_{i j} \frac{I_{j}}{N_{j}}
$$

300

where $\beta_{i j}$ is the transmission rate from the infectious individuals in patch $j$ to the susceptible

301 individuals in patch $i, N_{j}$ is the total number of individuals in patch $j$, and $n$ is the number of 302 patches.

303 In vector-borne disease modeling, the ideas of metapopulation have already been deeply

304 imbedded. The models always involve different subgroups, that is, the hosts and vectors. In many

305 cases, spatial distribution patterns were concurrently considered. As demonstrated in a previous

306 dengue study (Lee \& Castillo-Chavez, 2015), a two-patch model was constructed to explore the

307 influence of between-patch human movements on viral transmission dynamics. In the patches, the

308 SEIR and SEI models were architected for human and mosquito populations, respectively. This

309 was done to imitate how diseases spread within subpopulations. Another example is a study on the

310 impact of human movement on the dynamics and persistence of vector-borne diseases at the city

311 scale (Adams \& Kapan, 2009). The authors constructed metapopulation models which assume that

312 human population lives in a home patch free of mosquitoes but moves to and fro patches with

313 immobile mosquito subpopulations. Different human movement patterns were represented by

314 different connection patterns between human and mosquito subpopulations. It was found that 
315 more variable human movement pattern increases the influence of the large vector population

316 patches in establishing new foci of transmission and enhances pathogen persistence (Adams \&

317 Kapan, 2009). In Zika virus research, a metapopulation-typed model was constructed to investigate

318 the effects of sexual transmission and human migration in the spread of the virus (Baca-Carrasco

319 \& Velasco-Hernández, 2016). Recently, Zhang et al. expanded the Global Epidemic and Mobility

320 Model (GLEAM) (Balcan et al., 2010), a metapopulation model integrating real-world

321 demographic data and human mobility patterns, to incorporate data on mosquito density and

322 entomological-related parameters. The expanded GLEAM model was employed to analyze the

323 spread of the Zika virus in the Americas. It was estimated that the first introduction of the virus to

324 Brazil may have occurred between August 2013 and April 2014 (Zhang et al., 2017).

325

326 Network model

In fact, the interactions between actors in mathematical models are governed by the concept

328 of the contact network. It is assumed in the homogeneous compartmental model that all individuals

329 are linked by a regular random pattern (Bansal, Grenfell, \& Meyers, 2007). On the other hand, the

330 heterogeneous models, namely spatial and metapopulation, possess different assumptions that take

331 into account the higher realistic contact structures. The idea of a contact network emerged from

332 the mathematical graph theory and was first used in social sciences. Two fundamental components

333 that form a network are called "vertex" and "edge" (Lanzas \& Chen, 2015). A vertex is a unit of

334 interest for an individual, a group of people, a village, a city, or even an entire country. An edge is

335 the link between a pair of vertices. The edge represents the bond between vertices, which is

336 important in disease transmission, such as animal movement or human transportation. The

337 interaction is further divided into directed and undirected (Martínez-López, Perez, \& Sánchez- 
338 Vizcaíno, 2009), of which the directed links dictate the incoming and outgoing edges; for example,

339 flight itineraries, whereas the undirected approach does not consider directions, such as co-author

340 networks. In epidemiology, contact network modeling has often been used to investigate disease

341 transmission in both humans (Vazquez-Prokopec et al., 2013; Machens et al., 2013) and animals

342 (Craft, 2015; Rossi et al., 2017). The network structure exploration is helpful for targeting risk

343 actors and tailoring prevention and control strategies.

344 Determining a "real" network structure requires knowledge of all individuals in a

345 population and all possible relationships among them. In large networks, this is an impractical and

346 time-consuming task. However, several techniques have been exploited to approximate the

347 structure of the network, for example, a radio-based wearable device was used to identify high-

348 resolution close proximity interactions (less than 1.5 meters) among 75 individuals dwelling in 5

349 different households in rural Kenya (Kiti et al., 2016). The study makes it possible to collect a

350 high-resolution human contact data without any direct observations. Similar wireless sensor was

351 also used to explore social contact interactions among students, teachers and staff in an American

352 high school (Salathé et al., 2010). The network structure can also be approximated using movement

353 data, for example, airline route maps (Hufnagel, Brockmann \& Geisel, 2004) or livestock

354 movement patterns (Wiratsudakul et al., 2014; Chintrakulchai, Vuttichai \& Wiratsudakul, 2017;

355 Khengwa et al., 2017). However, these data sources have the disadvantage that the network

356 generally links sub-populations or groups of hosts rather than being a network between individuals.

357 Alternatively, the spatial contact proximity can be detected from mobile phones (Eagle et al., 2009)

358 or other Global Positioning System (GPS) data-loggers (Vazquez-Prokopec et al., 2013). Data

359 retrieved from these devices make the contact network to be more realistic which further improve

360 the accuracy of related epidemic models. 
361 Besides using approximated "real" networks, several forms of computer-generated

362 networks have also been employed in previous studies. Examples of these "idealized" networks

363 include a random network (Erdös \& Rényi, 1959; Gilbert, 1959), in which each pair of nodes is

364 connected randomly, and a scale-free network (Barabási \& Albert, 1999), where the probability

365 that a node is connected is proportional to its degree. These computer-generated networks are

366 proven to be useful in some aspects of infectious disease transmission (Keeling \& Eames, 2005;

367 Pastor-Satorras et al., 2015). A bipartite network, a network whose nodes are divided into two

368 separate groups with a scale-free degree distribution, was also used to simulate vector-borne

369 disease transmission (Bisanzio et al., 2010). The authors found that the spread of disease strongly

370 depends on the degree distribution of the two classes of nodes.

371 The contact network has also been used to describe disease transmission patterns in 372 mosquito-borne diseases. For instance, a previous study employed a contact-tracing investigation 373 to identify possible contact-site clusters. The authors suggested that house-to-house human 374 movement was likely to indicate how the dengue virus spread spatially (Stoddard et al., 2013).

375 This contact-identification technique is applicable to other mosquito-borne disease, including Zika 376 (Scatà et al., 2016; Saad-Roy, van den Driessche \& Ma, 2016).

378 Individual-based model

379 The individual-based approach, also known as the agent-based model, allows us to mimic 380 the complexity of individual interactions. Each individual can be explicitly simulated with a set of 381 characteristics including spatial location, interaction preference, behavior traits, etc. Moreover, 382 these state variables dictate how individuals interact with each other. However, they can change 383 over time (DeAngelis \& Grimm, 2014). Exploitation of the micro-level pattern (the bottom-up 
384 method) can prevent the rough estimation that inevitably occurs from the top-down approaches,

385 for example, the compartmental model. The individual-based model is powerful for the integration

386 of different scales and datasets. Therefore, it has been applied to various fields of scientific studies

387 (El-Sayed et al., 2012, Merler et al., 2015, Matheson, Satterthwaite, \& Highlander, 2017).

388 However, the trade-off between the model complexity and technological requirements must be

389 considered. The realistic models integrating large-scale real-word data apparently demand more

390 sophisticated machines (Lanzas \& Chen, 2015). Individual-based models have been extensively

391 applied to diseases that require highly unique individual features such as HIV/AIDS (White et al.,

392 2014), influenza (Eichner et al., 2014), tuberculosis (Graciani Rodrigues, Espíndola, \& Penna,

393 2015), and Ebola (Merler et al., 2015). In mosquito-borne diseases, individual-based models were

394 previously used to describe the transmission dynamics of the chikungunya virus (Dommar et al.,

395 2014), the dengue virus (Chao, Longini, \& Halloran, 2013), malaria (Pizzitutti et al., 2013), and

396 the Zika virus (Matheson, Satterthwaite, \& Highlander, 2017). It is noteworthy that state-of-the-

397 art structures, including the individual-based, metapopulation, and network models, are not

398 necessarily more realistic than compartmental models. Indeed, the advantage of these modeling

399 structures is that modelers are allowed to fully integrate the models with large-scale real-world

400 data. Consequently, such models are believed to be highly realistic (Lessler et al., 2016). A

401 graphical presentation of the basic models described in this review is illustrated in Figure 1.

402

403 Mathematical modeling for Zika virus epidemics

404 The Zika virus has been circulating among human beings for more than 70 years. However,

405 it has been in the sights of modelers for just a decade following a series of outbreaks on Yap Island.

406 Since then, a number of models have been proposed. This study compared some examples based 
407 on model structures and discussed the uses of mathematical models in Zika import risk estimation

408 and intervention planning.

409

410 Model architectures

411 As shown in Table 1, it is noticeable that Zika models carried out for early epidemics were

412 less complicated compared to the more recent ones. To our knowledge, the compartmental

413 approach was a fundamental framework for other sophisticated models that were recently

414 developed. In Zika modeling, all early works were fit into compartmental structures. It was

415 relatively fast and convenient to start with existing knowledge from other related diseases and

416 change the relevant parameters for the Zika virus. However, the compartmental model was still

417 regularly used as a backbone for later models.

418 Compartmentally, the crisscross transmission between humans and mosquitoes has been

419 popularly simulated. However, the models specially designed for only one (Monaghan et al., 2016;

420 Riou, Poletto, \& Boëlle, 2016; Scatà et al., 2016) or even another species (Althouse et al., 2015)

421 were also observed. Focusing on the model architecture, SEIR was usually used for humans

422 whereas SEI was commonly used for mosquitos. In addition, a model focusing only on human

423 compartments was recently proposed (Castro et al., 2017). Nonetheless, other compartmental

424 orientations were occasionally proposed, for example, the susceptible-infectious-recovered (SIR)

425 (Perkins et al., 2016), the susceptible-exposed-asymptomatic-infectious-recovered (SEAIR) (Gao

426 et al., 2016), the susceptible-preventive isolated-infectious-recovered ( $\left.\mathrm{Si}^{p} \mathrm{IR}\right)$, and the unaware-

427 aware-faded (UAF) models (Scatà et al., 2016).

428 Spatial models were developed to demonstrate how the Zika virus moves across 429 geographical spaces. Frequently, the spatial framework was complementarily driven by other types 
430 of models (Zinszer et al., 2017; Fitzgibbon, Morgan, \& Webb, 2017). The most prominent

431 advantage of the spatial models is their visualizing power. Apparently, the maps generated from

432 spatial modeling were the most comprehensible tools for the general public compared to other

433 model outputs. Hence, their final products, viral distribution maps, were frequently exploited in

434 public communication through various channels such as governmental authorities, mainstream

435 media, and even informal online platforms. The disease maps were widely used to increase public

436 awareness and to design specific prevention and control strategies for Zika (Rodriguez-Morales et

437 al., 2016) and other emerging diseases (Coburn \& Blower, 2013; Emmanuel, Isac, \& Blanchard, 438 2013; Koch, 2015).

439 We found that the early metapopulation, network, and individual-based models were 440 mostly structured without geographical or timeframe references (Table 1) (Scatà et al., 2016; Baca-

441 Carrasco \& Velasco-Hernández, 2016; Saad-Roy, van den Driessche, \& Ma, 2016). It seemed

442 difficult to immediately fit the real-world data into these sophisticated frameworks. However, not

443 long after the Zika epidemic started in Brazil, a data-driven metapopulation model incorporating

444 large-scale real-world data was presented (Zhang et al., 2017). The GLEAM model (Balcan et al., 445 2010) was expanded to incorporate data on mosquito density and other entomological-related 446 parameters (Zhang et al., 2017). Inclusion of these real-world data into the model is believed to 447 improve the ability of the model to reproduce the observed data and reliably predict future 448 epidemic dynamics.

450 Import risk model

451 Disease transmission models are developed to explore how a pathogen spreads in an 452 epidemic zone. However, the disease, especially a virus, may spread across the globe overnight. 
453 Therefore, an import risk model is used in this assessment. A particular framework is designed to

454 quantitatively assess the likelihood of viral importation into a certain territory. Such a model was

455 previously built to evaluate the importation risk of different emerging diseases, for instance, the

456 Ebola virus (Chen et al., 2014; Wiratsudakul et al., 2016), MERS-CoV (Nishiura et al., 2015; Nah

457 et al., 2016), and severe acute respiratory syndrome (SARS) (Goubar et al., 2009). For the Zika

458 virus, the imported cases were well documented in many countries on different continents (Pyke

459 et al., 2014; Bachiller-Luque et al., 2016; Jang et al., 2016; Sokal et al., 2016; Zhong et al., 2016;

460 Hashimoto et al., 2017; Xiang et al., 2017). The import risk models are necessary to foresee the

461 probability of Zika importation into other unaffected countries. As Brazil was recently in the

462 spotlight for Zika epidemics, models focused on the Zika virus escaping the country were

463 increasingly produced. In particular, models considering the risk of mass gatherings for

464 international events such as the Olympic games were recently proposed (Grills et al., 2016;

465 Massad, Coutinho, \& Wilder-Smith, 2016; Burattini et al., 2016). Herein, we described three basic

466 methods used in import risk estimation, deterministic and stochastic risk estimation and risk

467 estimation by force of infection.

468 Deterministic risk estimation

469 This method roughly calculated the probability of Zika virus importation into different 470 countries around the world via commercial air travel. In a previous model, the virus was designated 471 to spread from Brazil (Quam \& Wilder-Smith, 2016). The risk was formulated as $R_{I}$ $472=T \times I \times P$, where the risk $\left(R_{I}\right)$ is the product of the number of air passengers $(T)$ who traveled 473 from the Zika epidemic areas, the estimated infectious incidence per individual (I), and the 474 probability of infection in the travel period $(P)$. The results suggested that 584-1,786 Zika cases 475 may have been exported from Brazil during the 2014-2015 epidemics. 
476

477

478

479

480

481

484

485

486

487

488

489 First, the force of infection $\lambda$ was estimated from a Gaussian function $\lambda(t)=C_{1} \exp \left[-\frac{\left(t-C_{2}\right)^{2}}{C_{3}}\right] F(t)$,

$492=\frac{1}{1+\exp \left(-C_{4}\left(t-C_{5}\right)\right)}$, where $C_{4}$ and $C_{5}$ are the rate of incidence acceleration and the initial infection

\section{Stochastic risk estimation}

This process takes into account the stochasticity of travel volumes. The model was previously employed to estimate the risk of Ebola virus importation into the top 20 destination countries of travelers departing from the three Ebola epidemic countries in West Africa (Wiratsudakul et al., 2016). The risk was estimated using the binomial distribution $R_{n, e, t}$ $=\operatorname{Binom}\left(T_{n, e, t} \times I_{n, e, t}\right)$, where $R_{n, e, t}$ represents the risk of viral importation into country $n$ from affected country $e$ at time $t$ whereas $T_{n, e, t}$ and $I_{n, e, t}$ denote the corresponding number of flight travelers and outbreak country incidence, respectively. This simulation indicated that the risk of importing the Ebola virus during the peak of the epidemics could have reached 0.73 in Ghana, where the highest number of air passengers were observed.

Risk estimation by force of infection

This method was previously used in the import risk assessment for dengue virus diffusion from Brazil to other countries during the 2016 summer Olympic games (Ximenes et al., 2016). where $C_{1}$ determines the highest incidence, $C_{2}$ is the peak incidence time, and $C_{3}$ is the period of incidence function. $F(t)$ represents the ad hoc function, which is written in a logistic form as $F(t)$ time, respectively. Subsequently, $\lambda$ was used to calculate the risk of dengue infection during times

$494 t_{1}$ and $t_{2}$ as $\pi\left(t_{1}, t_{2}\right)=1-\exp \left[-\int_{t 1}^{t 2} \lambda(s) d s\right]$. This model scenario indicated that the number of 495 asymptomatic dengue cases among tourists may have reached 206 during the study period. 
499 framework to assess the effectiveness of different interventional strategies. For example, a

500 simulated outbreak scenario was examined for the performance of control measures against highly

501 pathogenic avian influenza in Ontario, Canada (Lewis et al., 2015). An import risk model was

502 tested for the mitigation capability of pandemic Ebola outbreaks through commercial air travel

503 restrictions (Wiratsudakul et al., 2016). The intervention models were also constructed for Zika.

504 A previous study exploited the prior knowledge of rubella control to construct a Zika virus

505 simulation. Rubella is a classic example of teratogenic agents causing viruses in humans. In

506 addition, the body of knowledge on rubella in terms of virology, epidemiology, and mathematical

507 modeling has been well documented (Metcalf \& Barrett, 2016). This is an excellent example of a

508 modeling framework derived from other well-known diseases. An intervention model for a related

509 emerging disease could be well supported in a timely fashion using such solid mathematical

510 environments.

511 Theoretical network modeling was also used in the strategic planning for Zika virus

512 outbreak alleviation (Scatà et al., 2016). The model selectively removed some specific vertices in

513 the network based on the eigenvector-like centrality and awareness values. Their findings

514 highlighted the importance of heterogeneity and public awareness in the control of infectious

515 diseases under different socioeconomic conditions. Prospectively, the authors planned to include

516 an analogy of HIV epidemics into the sexual transmission of Zika as well as an economic impact

517 evaluation of the disease (Scatà et al., 2016). For the economic aspects, a model addressing the

518 cost-effectiveness of Zika control interventions was proposed (Alfaro-Murillo et al., 2016). The

519 research team created a user-friendly online tool that was flexible enough to include new

520 parameters and provided a real-time analysis. The program facilitated the financial allocation and 
521 assessed its effectiveness. Another example is the economic appraisement of a newly established

522 policy. In the United States, blood centers were ordered to test for the Zika virus to prevent

523 transfusion-transmitted infection. An economic model was built to assess the implementation costs

524 and to suggest alternatives to reduce them (Ellingson et al., 2017). The model was essential for

525 predicting the overall investments and selecting the most cost-effective one. In addition to financial

526 management, other supporting facilities should also be considered. A previous study used a

527 modeling approach to assess the requirement of healthcare resources in real-time (Andronico et

528 al., 2017). The authors claimed that their model could provide an accurate prediction.

529 According to our examples, there are several ways to simulate strategic manipulation using

530 mathematical models. Most modelers designed their models based on existing or newly established

531 policies in order to guide policy makers and precisely meet the needs of societies. However, the

532 field data accuracy and baseline simulations directly affect the prediction power of strategic

533 models. One must seriously consider these factors before translating models into practices.

534

535 Perspectives on Zika virus epidemic models

536 We noticed that the compartmental model is still commonly used for the timely assessment

537 of epidemics. However, much more complex modeling frameworks (metapopulation, network, and

538 individual-based models) have been of increasing interest due to the recent availability of large-

539 scale real-world data and computational power. As we know, the computational capacity of

540 modern computers is presently very high. This allows us to deploy a sophisticated model to observe

541 the changes and predict the trends of disease dynamics in real-time. Moreover, the model will help

542 policy makers choose the most appropriate intervention to fight outbreaks and further assess the

543 corresponding results in a timely manner. In Zika virus modeling, state-of-the-art structures (the 
544 metapopulation, network, and individual-based models) have been increasingly developed using

545 advanced computational capacity. In other diseases such as Ebola, the real-word data was placed

546 into a complicated individual-based modeling framework. The study made it possible to produce

547 a more realistic output reflecting the actual outbreak situations (Merler et al., 2015).

548 "Big data" is an emerging field arising from the extremely large amount of data available

549 together with the advancement in computer infrastructures. In biomedical informatics, large-scale

550 health-related data shared among health professionals are undoubtedly beneficial for the

551 unprecedented development of healthcare services (Bellazzi, 2014). Automated modeling could

552 be enabled with the integration of big data and machine learning (Furqan et al., 2017). The future

553 of infectious disease modeling including vector-borne diseases may alter the classical methods.

554 Multiple modeling outputs may be generated automatically right after raw data are entered into

555 computers. However, there are some challenges, for example, the reproducibility of the results as

556 well as privacy and data reuse issues (Bellazzi, 2014).

557 In epidemiology, big data are increasingly being used to estimate disease spread and

558 investigate effectiveness of interventions. Recent works in infectious disease dynamics have been

559 characterized by an increasing focus on data-driven approaches. For example, the mobile call data

560 records (CDRs) have been used to explain the dynamics of large-scale Ebola outbreaks in West

561 Africa (Wesolowski et al., 2014). The CDR-based transmission models have also been employed

562 to analyze the spread of rubella disease in Kenya (Wesolowski et al., 2015). The individual-based

563 model that integrates detailed geographical and demographic data, and movements of individuals

564 was used to estimate the transmission of Ebola virus and investigate the effectiveness of

565 interventions in Liberia (Merler et al., 2015). For Zika, the data-driven metapopulation model

566 integrating real-world demographic, human mobility, socioeconomic, temperature, and vector 
567 density data has also been used to analyze the spread of the Zika virus in the Americas (Zhang et

568 al., 2017). These emerging data-driven approaches further allow the metapopulation, network, and

569 individual-based models better simulating the real epidemics.

570 In general, epidemic models can be used either as predictive tools or as a means of 571 understanding fundamental epidemiological processes. However, prediction is perhaps the most 572 obvious use of epidemic models. These allow us to predict the population-level epidemic dynamics 573 from an individual-level knowledge of epidemiological factors, and assess the effectiveness of 574 intervention strategies. As the trends in modeling of infectious diseases have been shifting towards 575 data-driven approaches (Lessler et al., 2016), the model complexity itself may hamper the use of 576 models by nonspecialists and public health practitioners. These complex modeling architectures 577 should be translated into a comprehensible environment. The modelers may adopt some strategies 578 taught in classes on translational medicine to evaluate how to turn epidemic models into practices. 579 Alternatively, user-friendly interfaces are helpful for health professionals to include mathematical 580 models in their strategic plans. For example, the GLEAM framework provides a user-friendly and 581 easy-to-use graphical tool for general modelers and public health agencies 582 (http://www.gleamviz.org). This is an excellent initiation of the translation of complex 583 mathematical models into a touchable framework. The results presented by Zhang et al. (2017) 584 were also delivered via user-friendly and easy-to-read graphics on a web application 585 (http://www.zika-model.org/). Therefore, an alliance with computer and graphical scientists is 586 encouraged. Moreover, some educational mobile applications are suggested to acquaint the general 587 public and especially younger generations with epidemic simulations. An excellent example is a 588 simulation game available at the App Store and Google Play called Plague Inc. (Ndemic Creations, 
589 Bristol, UK). The game makes mathematical models feel touchable and not too difficult, leading

590 to more familiarity and acceptance.

591 To fully implement mathematical modeling, one must persuade policy makers to include

592 the methods and try to prove that they are necessary. In this case, the translation of mathematical

593 language into political contexts is crucial. Moreover, simple and complex models should be

594 exploited differently. Simple models can be produced in a timely fashion to provide an estimation

595 of the possible impacts. In contrast, complex models require more time to develop but are far more

596 realistic. The models are much more powerful in terms of predictive capability. The preparation

597 of complicated models before outbreaks is recommended.

598

599 Conclusions

600 Mathematical models can be used either as predictive tools or as a means of understanding

601 fundamental epidemiological processes. This review provides basic knowledge of different 602 mathematical models used in studies of disease dynamics. We demonstrated how the models were 603 applied during the course of Zika virus outbreaks and discussed the uses of mathematical models 604 in Zika import risk estimation and intervention planning. We found that Zika models carried out 605 for early epidemics were less complicated compared to the more recent ones. The compartmental 606 model is still commonly used for the timely assessment of epidemics. However, more complex 607 modeling frameworks including metapopulation, network, and individual-based models have been 608 of increasing interest due to the recent availability of large-scale real-world data and computational 609 power. Inclusion of these real-world data into the model is believed to improve the ability of the 610 model to reproduce the observed data and reliably predict future epidemic dynamics. 


\section{Figure Legend}

613 Figure 1 Conceptual frameworks of different epidemic models. The colors represent 614 epidemiological status: susceptible (S, blue), exposed (E, gray), infectious (I, red), and recovered

615 (R, green). (A) Basic SIR compartmental model. Individuals are assumed to be well-mixed and 616 are classified only according to their epidemiological status. (B) Vector-borne compartmental 617 model. The subscripts $\mathrm{H}$ and $\mathrm{M}$ denote human and mosquito, respectively. Both host and vector 618 individuals are assumed to be well-mixed and are classified only according to their 619 epidemiological status. (C) Spatial model. Individuals are located at different locations. The 620 transmission of infection between an infectious individual and a susceptible individual at distance $621 x$ may occur with probability $K(x)$. (D) Metapopulation model. The entire population is divided 622 into two distinct subpopulations, each with independent disease transmission dynamics, together 623 with interactions between subpopulations. The subpopulation in each patch is mixed

624 homogeneously. (E) Network model. The model is formed by at least two basic components: 625 vertex and edge. Vertices are connected by edges defined by the relationship of interest such as 626 trade or travel. Infectious diseases are modeled to spread via the edges in this model. (F) 627 Individual-based model. In this most complicated model, the stochastic epidemiological dynamics 628 for each individual can be explicitly simulated with a set of characteristics including 629 epidemiological status, spatial location, interaction preference, behavior traits, etc.

\section{References}

632 Adams B., Kapan DD. 2009. Man bites mosquito: Understanding the contribution of human 633 movement to vector-borne disease dynamics. PLoS ONE 4:e6763. DOI:

$634 \quad 10.1371 /$ journal.pone.0006763. 
635 Akpa OM., Oyejola BA. 2010. Modeling the Transmission Dynamics of HIV/AIDS epidemics:

636 an introduction and a review. The Journal of Infection in Developing Countries 4:597-608.

637 DOI: $10.3855 /$ jidc.542.

638 Al-Qahtani AA., Nazir N., Al-Anazi MR., Rubino S., Al-Ahdal MN. 2016. Zika virus: a new

639 pandemic threat. Journal of infection in developing countries 10:201-7. DOI:

$640 \quad 10.3855 /$ jidc. 8350.

641 Alaniz AJ., Bacigalupo A., Cattan PE. 2017. Spatial quantification of the world population

642 potentially exposed to Zika virus. International Journal of Epidemiology 6:1-11. DOI:

$643 \quad 10.1093 / \mathrm{ije} / \mathrm{dyw} 366$.

644 Alfaro-Murillo JA., Parpia AS., Fitzpatrick MC., Tamagnan JA., Medlock J., Ndeffo-Mbah ML.,

645 Fish D., Avila-Aguero ML., Marin R., Ko AI., Galvani AP. 2016. A Cost-Effectiveness

646 Tool for Informing Policies on Zika Virus Control. PLoS Neglected Tropical Diseases

647 10:e0004743. DOI: 10.1371/journal.pntd.0004743.

648 Althouse BM., Hanley KA., Diallo M., Sall AA., Ba Y., Faye O., Diallo D., Watts DM., Weaver

649 SC., Cummings DAT. 2015. Impact of climate and mosquito vector abundance on sylvatic

650 arbovirus circulation dynamics in Senegal. The American journal of tropical medicine and

651 hygiene 92:88-97. DOI: 10.4269/ajtmh.13-0617.

652 Andronico A., Dorléans F., Fergé J-L., Salje H., Ghawché F., Signate A., Daudens-Vaysse E.,

653 Baudouin L., Dub T., Aubry M., Cao-Lormeau V-M., Ledrans M., Noel H., Mallet H-P.,

654 Fontanet A., Cabié A., Cauchemez S. 2017. Real-Time Assessment of Health-Care

655 Requirements During the Zika Virus Epidemic in Martinique. American Journal of

656 Epidemiology 10:1-10. DOI: 10.1093/aje/kwx008.

657 Asher J. 2017. Forecasting Ebola with a regression transmission model. Epidemics. DOI: 
10.1016/j.epidem.2017.02.009.

659

660

661

662

663

664

665

666

667

668

669

670

671

672

673

674

675

676

677

678

679

680

Baca-Carrasco D., Velasco-Hernández JX. 2016. Sex, Mosquitoes and Epidemics: An Evaluation of Zika Disease Dynamics. Bulletin of Mathematical Biology 78:2228-2242. DOI: $10.1007 / \mathrm{s} 11538-016-0219-4$.

Bachiller-Luque P., Domínguez-Gil González M., Álvarez-Manzanares J., Vázquez A., De Ory F., Sánchez-Seco Fariñas MP. 2016. First case of imported Zika virus infection in Spain. Enfermedades Infecciosas y Microbiologia Clinica 34:243-246. DOI: 10.1016/j.eimc.2016.02.012.

Balcan D., Gonçalves B., Hu H., Ramasco JJ., Colizza V., Vespignani A. 2010. Modeling the spatial spread of infectious diseases: The global epidemic and mobility computational model. Journal of Computational Science 1:132-145. DOI: 10.1016/j.jocs.2010.07.002.

Banos A., Corson N., Gaudou B., Laperrière V., Coyrehourcq S. 2015. The Importance of Being Hybrid for Spatial Epidemic Models:A Multi-Scale Approach. Systems 3:309-329. DOI: $10.3390 /$ systems 3040309 .

Bansal S., Grenfell BT., Meyers LA. 2007. When individual behaviour matters: homogeneous and network models in epidemiology. Journal of The Royal Society Interface 4:879-891. DOI: $10.1098 /$ rsif.2007.1100.

Barabási A-L., Albert R. 1999. Emergence of Scaling in Random Networks. Science 286:509_512. DOI: $10.1126 /$ science.286.5439.509.

Bernoulli D. 1766. Essai d'une nouvelle analyse de la mortalité causée par la petite vérole. Mém Math Phys Acad Roy Sci Paris 1:1-45.

Bellazzi R., 2014. Big Data and Biomedical Informatics: A Challenging Opportunity. IMIA Yearb 9:8-13. DOI:10.15265/IY-2014-0024 
681 Bisanzio D., Bertolotti L., Tomassone L., Amore G., Ragagli C., Mannelli A., Giacobini M., 682 Provero P. 2010. Modeling the spread of vector-borne diseases on bipartite networks. PLoS 683 ONE 5:e13796. DOI: 10.1371/journal.pone.0013796.

684 Browne C., Gulbudak H., Webb G. 2015. Modeling contact tracing in outbreaks with application 685 to Ebola. Journal of Theoretical Biology 384:33-49. DOI: 10.1016/j.jtbi.2015.08.004.

686 Burattini MN., Coutinho FAB., Lopez LF., Ximenes R., Quam M., Wilder-Smith A., Massad E. 687 2016. Potential exposure to Zika virus for foreign tourists during the 2016 Carnival and 688 Olympic Games in Rio de Janeiro, Brazil. Epidemiology and infection:1-3. DOI: $10.1017 / \mathrm{S} 0950268816000649$.

690 Cao-Lormeau V-M., Blake A., Mons S., Lastère S., Roche C., Vanhomwegen J., Dub T., 691 Baudouin L., Teissier A., Larre P., Vial A-L., Decam C., Choumet V., Halstead SK., 692 Willison HJ., Musset L., Manuguerra J-C., Despres P., Fournier E., Mallet H-P., Musso D., 693 Fontanet A., Neil J., Ghawché F. 2016. Guillain-Barre Syndrome outbreak associated with 694 Zika virus infection in French Polynesia: a case-control study. The Lancet 387:1531-1539. 695 DOI: $10.1016 / \mathrm{S} 0140-6736(16) 00562-6$.

696 Cao-Lormeau V-M., Roche C., Teissier A., Robin E., Berry A-L., Mallet H-P., Sall AA., Musso D. 2014. Zika virus, French polynesia, South pacific, 2013. Emerging infectious diseases

699 Castro LA., Fox SJ., Chen X., Liu K., Bellan SE., Dimitrov NB., Galvani AP., Meyers LA. 2017. $700 \quad$ Assessing real-time Zika risk in the United States. BMC Infectious Diseases 17:284. DOI: 701 10.1186/s12879-017-2394-9.

702 Champagne C., Salthouse DG., Paul R., Cao-Lormeau VM., Roche B., Cazelles B. 2016.

703 Structure in the variability of the basic reproductive number (R0) for Zika epidemics in the 
$704 \quad$ Pacific islands. eLife 5. DOI: 10.7554/eLife.19874.

705 Chao DL., Longini IM., Halloran ME. 2013. The Effects of Vector Movement and Distribution

706 in a Mathematical Model of Dengue Transmission. PLoS ONE 8:e76044. DOI:

$707 \quad$ 10.1371/journal.pone.0076044.

708 Chen T., Ka-Kit Leung R., Liu R., Chen F., Zhang X., Zhao J., Chen S. 2014. Risk of imported

709 Ebola virus disease in China. Travel medicine and infectious disease 12:650-658. DOI:

$710 \quad$ 10.1016/j.tmaid.2014.10.015.

711 Chintrakulchai P., Vuttichai S., Wiratsudakul A. 2017. Goat movement network analysis and its

712 implications for caprine brucellosis propagation in Nonthaburi Province, Thailand. Asian

713 Pacific Journal of Tropical Disease 7:477-481. DOI: 10.12980/apjtd.7.2017D7-85.

714 Coburn BJ., Blower S. 2013. Mapping HIV epidemics in sub-Saharan Africa with use of GPS

715 data. The Lancet Global Health 1:e251-e253. DOI: 10.1016/S2214-109X(13)70084-6.

716 Craft ME. 2015. Infectious disease transmission and contact networks in wildlife and livestock.

717 Philosophical Transactions of the Royal Society B: Biological Sciences 370:20140107-

$718 \quad 20140107$. DOI: $10.1098 /$ rstb.2014.0107.

719 Crowder DW., Dykstra EA., Brauner JM., Duffy A., Reed C., Martin E., Peterson W., Carrière

720 Y., Dutilleul P., Owen JP. 2013. West Nile Virus Prevalence across Landscapes Is Mediated

721 by Local Effects of Agriculture on Vector and Host Communities. PLoS ONE 8:e55006.

722 DOI: 10.1371/journal.pone.0055006.

723 DeAngelis DL., Grimm V. 2014. Individual-based models in ecology after four decades.

724 F1000Prime Reports 6. DOI: 10.12703/P6-39.

725 Delmelle E., Hagenlocher M., Kienberger S., Casas I. 2016. A spatial model of socioeconomic

726 and environmental determinants of dengue fever in Cali, Colombia. Acta Tropica 164:169- 
176. DOI: 10.1016/j.actatropica.2016.08.028.

728 Dick GW., Kitchen S., Haddow A. 1952. Zika Virus (I). Isolations and serological specificity.

729 Transactions of the Royal Society of Tropical Medicine and Hygiene 46:509-520. DOI:

$730 \quad 10.1016 / 0035-9203(52) 90042-4$

731 Diekmann O., Heesterbeek J., Roberts M. 2010. The construction of next-generation matrices for 732 compartmental epidemic models. Journal of the Royal Society Interface 7:873-885. DOI:

$733 \quad$ 10.1098/rsif.2009.0386.

734 Dommar CJ., Lowe R., Robinson M., Rod?? X. 2014. An agent-based model driven by tropical

735 rainfall to understand the spatio-temporal heterogeneity of a chikungunya outbreak. Acta

736 Tropica 129:61-73. DOI: 10.1016/j.actatropica.2013.08.004.

737 Duffy MR., Chen T-H., Hancock WT., Powers AM., Kool JL., Lanciotti RS., Pretrick M., Marfel

738 M., Holzbauer S., Dubray C., Guillaumot L., Griggs A., Bel M., Lambert AJ., Laven J.,

739 Kosoy O., Panella A., Biggerstaff BJ., Fischer M., Hayes EB. 2009. Zika virus outbreak on

$740 \quad$ Yap Island, Federated States of Micronesia. The New England journal of medicine

$741 \quad 360: 2536-43$. DOI: 10.1056/NEJMoa0805715.

742 Eagle N., Pentland AS., Lazer D. 2009. Inferring friendship network structure by using mobile

743 phone data. Proceedings of the National Academy of Sciences of the United States of

744 America 106:15274-8. DOI: 10.1073/pnas.0900282106.

745 Eichner M., Schwehm M., Hain J., Uphoff H., Salzberger B., Knuf M., Schmidt-Ott R. 2014.

$746 \quad 4 F l u$ - an individual based simulation tool to study the effects of quadrivalent vaccination on

747 seasonal influenza in Germany. BMC Infectious Diseases 14:365. DOI: 10.1186/1471-2334-

$748 \quad 14-365$.

749 El-Sayed AM., Scarborough P., Seemann L., Galea S. 2012. Social network analysis and agent- 

based modeling in social epidemiology. Epidemiologic perspectives \& innovations : EP+I 9:1. DOI: 10.1186/1742-5573-9-1.

752 Ellingson KD., Sapiano MRP., Haass KA., Savinkina AA., Baker ML., Henry RA., Berger JJ.,

753 Kuehnert MJ., Basavaraju S V. 2017. Cost projections for implementation of safety

754 interventions to prevent transfusion-transmitted Zika virus infection in the United States. Transfusion 57:1625-1633. DOI: 10.1111/trf.14164.

756

757

758

759

760

761

762

763

764

765

766

767

768

769

770

771

772

Emmanuel F., Isac S., Blanchard JF. 2013. Using geographical mapping of key vulnerable populations to control the spread of HIV epidemics. Expert review of anti-infective therapy 11:451-453. DOI: 10.1586/eri.13.33.

Erdös., Rényi A. 1959. On random graphs, I. Publicationes Mathematicae (Debrecen) 6:290297.

Fitzgibbon WE., Morgan JJ., Webb GF. 2017. An outbreak vector-host epidemic model with spatial structure: the 2015-2016 Zika outbreak in Rio De Janeiro. Theoretical Biology and Medical Modelling 14:7. DOI: 10.1186/s12976-017-0051-z.

Funk S., Kucharski AJ., Camacho A., Eggo RM., Yakob L., Murray LM., Edmunds WJ. 2016. Comparative Analysis of Dengue and Zika Outbreaks Reveals Differences by Setting and Virus. PLOS Neglected Tropical Diseases 10:e0005173. DOI:

10.1371/journal.pntd.0005173.

Furqan, H.T., Wahab, A.A., Sadiq, S., Ali Shah, P.A., 2017. Ready Mealy, Moore \&amp; Markov Mathematical Modeling Machines for Big Data, in: International Conference on Future Intelligent Vehicular Technologies. Springer, Cham, pp. 205-214. doi:10.1007/9783-319-51207-5_21

Gao D., Lou Y., He D., Porco TC., Kuang Y., Chowell G., Ruan S. 2016. Prevention and control 
Gilbert EN. 1959. Random Graphs. The Annals of Mathematical Statistics 30:1141-1144. DOI: 10.1214/aoms/1177706098.

777 Goeijenbier M., Slobbe L., van der Eijk A., de Mendonça Melo M., Koopmans MPG., Reusken

778 CBEM. 2016. Zika virus and the current outbreak: an overview. The Netherlands journal of medicine 74:104-109.

Goubar A., Bitar D., Cao WC., Feng D., Fang LQ., Desenclos JC. 2009. An approach to estimate 781 the number of SARS cases imported by international air travel. Epidemiology and infection 137:1019-31. DOI: 10.1017/S0950268808001635.

Graciani Rodrigues CC., Espíndola AL., Penna TJP. 2015. An agent-based computational model Importation and Subsequent Ongoing Transmission after Travel to the 2016 Olympic and Paralympic Games — Country-Specific Assessment, July 2016. MMWR. Morbidity and Mortality Weekly Report 65:711-715. DOI: 10.15585/mmwr.mm6528e1.

de Groot RJ., Baker SC., Baric RS., Brown CS., Drosten C., Enjuanes L., Fouchier RAM., 791 Galiano M., Gorbalenya AE., Memish ZA., Perlman S., Poon LLM., Snijder EJ., Stephens

792 GM., Woo PCY., Zaki AM., Zambon M., Ziebuhr J. 2013. Middle East respiratory

793 syndrome coronavirus (MERS-CoV): announcement of the Coronavirus Study Group. Journal of virology 87:7790-7792. DOI: 10.1128/JVI.01244-13.

795 Harrigan RJ., Thomassen HA., Buermann W., Smith TB. 2014. A continental risk assessment of 
West Nile virus under climate change. Global Change Biology 20:2417-2425. DOI:

797 $10.1111 / \mathrm{gcb} .12534$.

Hashimoto T., Kutsuna S., Tajima S., Nakayama E., Maeki T., Taniguchi S., Lim CK., Katanami Y., Takeshita N., Hayakawa K., Kato Y., Ohmagari N. 2017. Importation of Zika virus from Vietnam to Japan, November 2016. Emerging Infectious Diseases 23:1222-1225. DOI:

801 10.3201/eid2307.170519.

802

Hayes EB. 2009. Zika virus outside Africa. Emerging infectious diseases 15:1347-1350. DOI: 10.3201/eid1509.090442.

Hethcote HW. 2000. The Mathematics of Infectious Diseases. SIAM Review 42:599-653. DOI:

805 $10.1137 / \mathrm{S} 0036144500371907$.

Heymann DL., Hodgson A., Sall AA., Freedman DO., Staples JE., Althabe F., Baruah K., 807 Mahmud G., Kandun N., Vasconcelos PFC., Bino S., Menon KU. 2016. Zika virus and microcephaly: why is this situation a PHEIC? The Lancet 387:719-721. DOI:

Hufnagel L., Brockmann D., Geisel T. 2004. Forecast and control of epidemics in a globalized world. Proceedings of the National Academy of Sciences 101:15124-15129. DOI: 10.1073/pnas.0308344101.

813 Jang HC., Park WB., Kim UJ., Chun JY., Choi SJ., Choe PG., Jung SI., Jee Y., Kim NJ., Choi 814 EH., Oh MD. 2016. First Imported Case of Zika Virus Infection into Korea. Journal of $815 \quad$ Korean medical science 31:1173-1177. DOI: $10.3346 / \mathrm{jkms.2016.31.7.1173.}$

816 de Jong MCM., Hagenaars TJ. 2009. Modelling control of avian influenza in poultry: the link 817 with data. Revue scientifique et technique (International Office of Epizootics) 28:371-377.

818 Keeling MJ., Eames KTD. 2005. Networks and epidemic models. Journal of the Royal Society, 
Interface / the Royal Society 2:295-307. DOI: 10.1098/rsif.2005.0051.

820 Khengwa C., Jongchansittoe P., Sedwisai P., Wiratsudakul A. 2017. A traditional cattle trade

821 network in Tak province, Thailand and its potential in the spread of infectious diseases.

$822 \quad$ Animal Production Science 57:152. DOI: 10.1071/AN15043.

823 Kermack WO., McKendrick AG. 1927. A Contribution to the Mathematical Theory of

824 Epidemics. Proceedings of the Royal Society A: Mathematical, Physical and Engineering

$825 \quad$ Sciences 115:700-721. DOI: 10.1098/rspa.1927.0118.

826 Kermack WO., McKendrick AG. 1932. Contributions to the Mathematical Theory of Epidemics.

827 II. The Problem of Endemicity. Proceedings of the Royal Society A: Mathematical, Physical $828 \quad$ and Engineering Sciences 138:55-83. DOI: 10.1098/rspa.1932.0171.

829 Kermack WO., McKendrick AG. 1933. Contributions to the Mathematical Theory of Epidemics.

830 III. Further Studies of the Problem of Endemicity. Proceedings of the Royal Society A:

$831 \quad$ Mathematical, Physical and Engineering Sciences 141:94-122. DOI:

832 10.1098/rspa.1933.0106.

Khan A., Naveed M., Dur-e-Ahmad M., Imran M. 2015. Estimating the basic reproductive ratio for the Ebola outbreak in Liberia and Sierra Leone. Infectious Diseases of Poverty 4:13. DOI: $10.1186 / \mathrm{s} 40249-015-0043-3$.

836 Kindhauser MK., Allen T., Frank V., Santhana RS., Dye C. 2016. Zika: the origin and spread of 837 a mosquito-borne virus. Bull World Health Organ 94:675-686C. DOI: http://dx.doi.org/10.2471/BLT.16.171082.

Kiti MC., Tizzoni M., Kinyanjui TM., Koech DC., Munywoki PK., Meriac M., Cappa L.,

840 Panisson A., Barrat A., Cattuto C., Nokes DJ. 2016. Quantifying social contacts in a 841 household setting of rural Kenya using wearable proximity sensors. EPJ Data Science 5:21. 
DOI: 10.1140/epjds/s13688-016-0084-2.

843 Koch T. 2015. Mapping medical disasters: ebola makes old lessons, new. Disaster medicine and 844 public health preparedness 9:66-73. DOI: 10.1017/dmp.2015.14.

845 Kucharski AJ., Funk S., Eggo RM., Mallet HP., Edmunds WJ., Nilles EJ. 2016. Transmission 846 Dynamics of Zika Virus in Island Populations: A Modelling Analysis of the 2013-2014

847 French Polynesia Outbreak. PLoS Neglected Tropical Diseases 10:e0004726. DOI: $848 \quad$ 10.1371/journal.pntd.0004726.

849 Lanzas C., Chen S. 2015. Complex system modelling for veterinary epidemiology. Preventive $850 \quad$ Veterinary Medicine 118:207-214. DOI: 10.1016/j.prevetmed.2014.09.012.

851 Lawson AB. 2013. Statistical methods in spatial epidemiology. Wiley.

852 Lee SY., Baek GY., Choi EG., Kim CH., Kim TH., Son WG., Kim KY., Kim HT. 2013.

853 Analysis of FMD(Foot and Mouth Disease) Diffusion Route by using GIS in Gyeongbuk 854 Area. IFAC Proceedings Volumes 46:176-180. DOI: 10.3182/20130327-3-JP-3017.00040.

855 Lee S., Castillo-Chavez C. 2015. The role of residence times in two-patch dengue transmission 856 dynamics and optimal strategies. Journal of Theoretical Biology 374:152-164. DOI: $857 \quad$ 10.1016/j.jtbi.2015.03.005.

858 Lessler J., Azman AS., Grabowski MK., Salje H., Rodriguez-Barraquer I. 2016. Trends in the 859 Mechanistic and Dynamic Modeling of Infectious Diseases. Current Epidemiology Reports $860 \quad 3: 212-222$. DOI: 10.1007/s40471-016-0078-4.

861 Lessler J., Salje H., Grabowski MK., Cummings DAT., Buddhari D., Nisalak A., Silva A de. 862 2016. Measuring Spatial Dependence for Infectious Disease Epidemiology. PLOS ONE 863 11:e0155249. DOI: 10.1371/journal.pone.0155249.

864 Levins R. 1969. Some Demographic and Genetic Consequences of Environmental Heterogeneity 
865 for Biological Control. Bulletin of the Entomological Society of America 15:237-240. DOI:

$866 \quad 10.1093 /$ besa/15.3.237.

867 Lewis N., Dorjee S., Dubé C., Vanleeuwen J., Sanchez J. 2015. Assessment of Effectiveness of

868 Control Strategies Against Simulated Outbreaks of Highly Pathogenic Avian Influenza in

869 Ontario, Canada. Transboundary and Emerging Diseases 64:938-950. DOI:

$870 \quad 10.1111 /$ tbed.12461.

871 Lin Z., Zhu H. 2017. Spatial spreading model and dynamics of West Nile virus in birds and

872 mosquitoes with free boundary. Journal of Mathematical Biology:1-29. DOI:

$873 \quad 10.1007 / \mathrm{s} 00285-017-1124-7$.

874 Lopes MH., Miyaji KT., Infante V., Lopes MH., Miyaji KT., Infante V. 2016. Zika virus. Revista 875 da Associação Médica Brasileira 62:4-9. DOI: 10.1590/1806-9282.62.01.4.

876 Lucey DR., Gostin LO. 2016. The emerging Zika pandemic: enhancing preparedness. JAMA $877 \quad 315: 865-866$.

878 Luo S., Han L., Lu H., Dou Z., Tao Q., Khoshnood K., Wu Z., Xu J. 2015. Evaluating the Impact

879 of Test-and-Treat on the HIV Epidemic among MSM in China Using a Mathematical

$880 \quad$ Model. PLOS ONE 10:e0126893. DOI: 10.1371/journal.pone.0126893.

881 MacDonald G. 1952. The analysis of equilibrium in malaria. Tropical diseases bulletin 49:81388229.

883 Machens A., Gesualdo F., Rizzo C., Tozzi AE., Barrat A., Cattuto C. 2013. An infectious disease

884 model on empirical networks of human contact: bridging the gap between dynamic network

885 data and contact matrices. BMC Infectious Diseases 13:185. DOI: 10.1186/1471-2334-13-

$886 \quad 185$.

887 Mackey TK., Liang BA. 2012. Lessons from SARS and H1N1/A: Employing a WHO-WTO 
888 forum to promote optimal economic-public health pandemic response. Journal of Public $889 \quad$ Health Policy 33:119-130. DOI: 10.1057/jphp.2011.51.

890 MacNamara F. 1954. Zika virus : A report on three cases of human infection during an epidemic 891 of jaundice in Nigeria. Transactions of the Royal Society of Tropical Medicine and Hygiene 892 48:139-145. DOI: 10.1016/0035-9203(54)90006-1.

893 Martínez-López B., Perez AM., Sánchez-Vizcaíno JM. 2009. Social network analysis. Review of 894 general concepts and use in preventive veterinary medicine. Transboundary and Emerging 895 Diseases 56:109-120. DOI: 10.1111/j.1865-1682.2009.01073.x.

896 Massad E., Coutinho FA ntonio B., Wilder-Smith A. 2016. Is Zika a substantial risk for visitors 897 to the Rio de Janeiro Olympic Games? Lancet (London, England) 388:25. DOI:

$898 \quad$ 10.1016/S0140-6736(16)30842-X.

899 Matheson T., Satterthwaite B., Highlander HC. 2017. Modeling the Spread of the Zika Virus at 900 the 2016 Olympics. Spora: A Journal of Biomathematics 3.

901 Matthew Glomski., Edward Ohanian. 2012. Eradicating a Disease: Lessons from Mathematical 902 Epidemiology. The College Mathematics Journal 43:123. DOI:

$903 \quad$ 10.4169/college.math.j.43.2.123.

904 McVernon J., McCaw C., Mathews J. 2007. Model answers or trivial pursuits? The role of 905 mathematical models in influenza pandemic preparedness planning. Influenza and Other 906 Respiratory Viruses 1:43-54. DOI: 10.1111/j.1750-2659.2007.00008.x.

907 Merler S., Ajelli M., Fumanelli L., Gomes MFC., Piontti APY., Rossi L., Chao DL., Longini 908 IM., Halloran ME., Vespignani A. 2015. Spatiotemporal spread of the 2014 outbreak of 909 Ebola virus disease in Liberia and the effectiveness of non-pharmaceutical interventions: A 910 computational modelling analysis. The Lancet Infectious Diseases 15:204-211. DOI: 
912 Metcalf CJE., Barrett A. 2016. Invasion Dynamics of Teratogenic Infections in Light of Rubella 913 Control: Implications for Zika Virus. PLoS Currents. DOI:

$914 \quad 10.1371 /$ currents.outbreaks.873427b89ab9c75eb90c8ddb8d8c7c90.

915 Mlakar J., Korva M., Tul N., Popović M., Poljšak-Prijatelj M., Mraz J., Kolenc M., Resman Rus

916 K., Vesnaver Vipotnik T., Fabjan Vodušek V., Vizjak A., Pižem J., Petrovec M., Avšič

917 Županc T. 2016. Zika Virus Associated with Microcephaly. New England Journal of

918 Medicine 374:951-958. DOI: 10.1056/NEJMoa1600651\%M 26862926\%U

919 http://www.nejm.org/doi/full/10.1056/NEJMoa1600651.

920 Monaghan AJ., Morin CW., Steinhoff DF., Wilhelmi O., Hayden M., Quattrochi DA., Reiskind

921 M., Lloyd AL., Smith K., Schmidt CA., Scalf PE., Ernst K. 2016. On the Seasonal

922 Occurrence and Abundance of the Zika Virus Vector Mosquito Aedes Aegypti in the

923 Contiguous United States. PLoS Currents 8. DOI:

924 10.1371/currents.outbreaks.50dfc7f46798675fc63e7d7da563da76.

925 Musso D. 2015. Zika Virus Transmission from French Polynesia to Brazil. Emerging infectious 926 diseases 21:1887. DOI: 10.3201/eid2110.151125.

927 Nah K., Otsuki S., Chowell G., Nishiura H. 2016. Predicting the international spread of Middle 928 East respiratory syndrome (MERS). BMC infectious diseases 16:356. DOI:

$929 \quad 10.1186 / \mathrm{s} 12879-016-1675-\mathrm{z}$.

930 Nishiura H., Kinoshita R., Mizumoto K., Yasuda Y., Nah K. 2016a. Transmission potential of 931 Zika virus infection in the South Pacific. International Journal of Infectious Diseases 932 45:95-97. DOI: 10.1016/j.ijid.2016.02.017.

933 Nishiura H., Miyamatsu Y., Chowell G., Saitoh M. 2015. Assessing the risk of observing 
934 multiple generations of middle east respiratory syndrome (MERS) cases given an imported 935 case. Eurosurveillance 20:6-11. DOI: 10.2807/1560-7917.ES2015.20.27.21181.

936 Nishiura H., Mizumoto K., Villamil-G?mez WE., Rodr?guez-Morales AJ. 2016b. Preliminary

937 estimation of the basic reproduction number of Zika virus infection during Colombia

938 epidemic, 2015-2016. Travel Medicine and Infectious Disease 14:274-276. DOI:

$939 \quad$ 10.1016/j.tmaid.2016.03.016.

940 de Oliveira WK., Carmo EH., Henriques CM., Coelho G., Vazquez E., Cortez-Escalante J.,

941 Molina J., Aldighieri S., Espinal MA., Dye C. 2017. Zika Virus Infection and Associated

942 Neurologic Disorders in Brazil. New England Journal of Medicine 376:1591-1593. DOI:

$943 \quad$ 10.1056/NEJMc1608612.

944 de Oliveira CS., da Costa Vasconcelos PF. 2016. Microcephaly and Zika virus. Jornal de

945 pediatria 92:103-5. DOI: 10.1016/j.jped.2016.02.003.

946 Pastor-Satorras R., Castellano C., Van Mieghem P., Vespignani A. 2015. Epidemic processes in 947 complex networks. Reviews of Modern Physics 87:925-979. DOI:

$948 \quad$ 10.1103/RevModPhys.87.925.

949 Perkins TA., Siraj AS., Ruktanonchai CW., Kraemer MUG., Tatem AJ. 2016. Model-based

950 projections of Zika virus infections in childbearing women in the Americas. Nature

$951 \quad$ Microbiology 1:16126. DOI: 10.1038/nmicrobiol.2016.126.

952 Petersen LR., Jamieson DJ., Powers AM., Honein MA. 2016. Zika Virus. The New England

953 journal of medicine. DOI: 10.1056/NEJMra1602113.

954 Pizzitutti F., Pan W., Barbieri A., Miranda JJ., Feingold B., Guedes GR., Alarcon-Valenzuela J.,

955 Mena CF. 2013. Malaria Policy Advisory Committee to the WHO: conclusions and

956 recommendations of March 2013 meeting. Malaria Journal 12:213. DOI: 10.1186/1475- 
958 Pyke AT., Daly MT., Cameron JN., Moore PR., Taylor CT., Hewitson GR., Humphreys JL.,

959 Gair R. 2014. Imported zika virus infection from the cook islands into australia, 2014. PLoS

960 currents 6:1-7. DOI: 10.1371/currents.outbreaks.4635a54dbffba2156fb2fd76dc49f65e.

961 Quam MB., Wilder-Smith A. 2016. Estimated global exportations of Zika virus infections via

962 travellers from Brazil from 2014 to 2015. Journal of travel medicine 23:taw059. DOI:

$963 \quad 10.1093 /$ jtm/taw059.

964 Riou J., Poletto C., Boëlle PY. 2016. A comparative analysis of Chikungunya and Zika

965 transmission. Epidemics 19:43-52. DOI: 10.1016/j.epidem.2017.01.001.

966 Rock K., Brand S., Moir J., Keeling MJ. 2014a. Dynamics of infectious diseases. Reports on

967 Progress in Physics 77:26602. DOI: 10.1088/0034-4885/77/2/026602.

968 Rock K., Brand S., Moir J., Keeling MJ. 2014b. Dynamics of infectious diseases. Reports on

969 Progress in Physics 77:26602. DOI: 10.1088/0034-4885/77/2/026602.

970 Rodriguez-Morales AJ., Patiño-Cadavid LJ., Lozada-Riascos CO., Villamil-Gómez WE. 2016.

971 Mapping Zika in municipalities of one coastal department of Colombia (Sucre) using

972 geographic information systems during the 2015-2016 outbreak: implications for public

973 health and travel advice. International Journal of Infectious Diseases 48:70-72. DOI:

$974 \quad$ 10.1016/j.ijid.2016.05.012.

975 Ross R. 1911. The prevention of malaria. In: London: John Murray, 651-686.

976 Rossi G., Smith RL., Pongolini S., Bolzoni L. 2017. Modelling farm-to-farm disease

977 transmission through personnel movements: from visits to contacts, and back. Scientific

978 Reports 7:2375. DOI: 10.1038/s41598-017-02567-6.

979 Saad-Roy CM., van den Driessche P., Ma J. 2016. Estimation of Zika virus prevalence by 

appearance of microcephaly. BMC Infectious Diseases 16:754. DOI: 10.1186/s12879-016-

981 2076-z.

982 Salathé M., Kazandjieva M., Lee JW., Levis P., Feldman MW., Jones JH. 2010. A high-

983 resolution human contact network for infectious disease transmission. Proceedings of the

984 National Academy of Sciences of the United States of America 107:22020-5. DOI:

$985 \quad 10.1073 /$ pnas. 1009094108.

986 Santermans E., Robesyn E., Ganyani T., Sudre B., Faes C., Quinten C., Van Bortel W., Haber T.,

987 Kovac T., Van Reeth F., Testa M., Hens N., Plachouras D. 2016. Spatiotemporal Evolution

988 of Ebola Virus Disease at Sub-National Level during the 2014 West Africa Epidemic:

989 Model Scrutiny and Data Meagreness. PLOS ONE 11:e0147172. DOI:

$990 \quad$ 10.1371/journal.pone.0147172.

991 Sardar T., Saha B. 2017. Mathematical analysis of a power-law form time dependent vector992 borne disease transmission model. Mathematical Biosciences 288:109-123. DOI:

$993 \quad$ 10.1016/j.mbs.2017.03.004.

994 Scatà M., Di Stefano A., Liò P., La Corte A. 2016. The Impact of Heterogeneity and Awareness 995 in Modeling Epidemic Spreading on Multiplex Networks. Scientific Reports 6:37105. DOI: $996 \quad 10.1038 / \operatorname{srep} 37105$.

997 Shi W., Zhang Z., Ling C., Carr MJ., Tong Y., Gao GF. 2016. Increasing genetic diversity of 998 Zika virus in the Latin American outbreak. Emerging microbes \& infections 5:e68. DOI: $999 \quad$ 10.1038/emi.2016.68.

1000 Sidiki A., Tchuente M. 2014. The Basic Reproduction Number for Cellular SIR Networks. Acta 1001 Biotheoretica 62:417-427. DOI: 10.1007/s10441-014-9231-y.

1002 Smith DL., Battle KE., Hay SI., Barker CM., Scott TW., McKenzie FE. 2012. Ross, macdonald, 
1003

1004

1005

1006

1007

1008

1009

1010

1011

1012

1013

1014

1015

1016

1017

1018

1019

1020

1021

1022

1023

1024

1025

and a theory for the dynamics and control of mosquito-transmitted pathogens. PLoS pathogens 8:e1002588. DOI: 10.1371/journal.ppat.1002588.

Sokal A., D’Ortenzio E., Houhou-Fidouh N., Brichler S., Dorchies J., Cabras O., Leparc-Goffart I., Yazdanpanah Y., Matheron S. 2016. Zika virus infection: report of the first imported cases in a Paris travel centre. Journal of Travel Medicine 24:taw066. DOI: $10.1093 / \mathrm{jtm} / \mathrm{taw} 066$

Sornbundit K., Triampo W., Modchang C. 2017. Mathematical modeling of diphtheria transmission in Thailand. Computers in Biology and Medicine 87:162-168. DOI: 10.1016/j.compbiomed.2017.05.031.

Stoddard ST., Forshey BM., Morrison AC., Paz-Soldan VA., Vazquez-Prokopec GM., Astete H., Reiner RC., Vilcarromero S., Elder JP., Halsey ES., Kochel TJ., Kitron U., Scott TW. 2013. House-to-house human movement drives dengue virus transmission. Proceedings of the National Academy of Sciences 110:994-999. DOI: 10.1073/pnas.1213349110.

Szmaragd C., Wilson AJ., Carpenter S., Wood JLN., Mellor PS., Gubbins S. 2009. A modeling framework to describe the transmission of bluetongue virus within and between farms in Great Britain. PloS one 4:e7741. DOI: 10.1371/journal.pone.0007741.

Tabachnick WJ. 2016. Ecological effects on arbovirus-mosquito cycles of transmission. Current Opinion in Virology 21:124-131. DOI: 10.1016/j.coviro.2016.09.008.

Tobler WR. 1970. A Computer Movie Simulating Urban Growth in the Detroit Region. Economic Geography 46:234. DOI: 10.2307/143141.

Tognarelli J., Ulloa S., Villagra E., Lagos J., Aguayo C., Fasce R., Parra B., Mora J., Becerra N., Lagos N., Vera L., Olivares B., Vilches M., Fernández J. 2015. A report on the outbreak of Zika virus on Easter Island, South Pacific, 2014. Archives of virology 161:665-8. DOI: 
Vazquez-Prokopec GM., Bisanzio D., Stoddard ST., Paz-Soldan V., Morrison AC., Elder JP.,

1028 Ramirez-Paredes J., Halsey ES., Kochel TJ., Scott TW., Kitron U. 2013. Using GPS

1029 Technology to Quantify Human Mobility, Dynamic Contacts and Infectious Disease

1030 Dynamics in a Resource-Poor Urban Environment. PLoS ONE 8:e58802. DOI:

$1031 \quad$ 10.1371/journal.pone.0058802.

1032 Vest KG. 2016. Zika Virus: A Basic Overview of an Emerging Arboviral Infection in the

1033 Western Hemisphere. Disaster medicine and public health preparedness:1-6. DOI:

$1034 \quad$ 10.1017/dmp.2016.43.

1035 Vincenti-Gonzalez MF., Grillet M-E., Velasco-Salas ZI., Lizarazo EF., Amarista MA., Sierra

1036 GM., Comach G., Tami A. 2017. Spatial Analysis of Dengue Seroprevalence and Modeling

1037 of Transmission Risk Factors in a Dengue Hyperendemic City of Venezuela. PLOS

$1038 \quad$ Neglected Tropical Diseases 11:e0005317. DOI: 10.1371/journal.pntd.0005317.

1039 Wang L., Li X. 2014. Spatial epidemiology of networked metapopulation: an overview. Chinese

$1040 \quad$ Science Bulletin 59:3511-3522. DOI: 10.1007/s11434-014-0499-8.

1041 Wesolowski A., Buckee CO., Bengtsson L., Wetter E., Lu X., Tatem AJ. 2014. Commentary:

1042 Containing the Ebola Outbreak - the Potential and Challenge of Mobile Network Data.

1043 PLoS Currents Outbreaks:1-17. DOI:

$1044 \quad$ 10.1371/currents.outbreaks.0177e7fcf52217b8b634376e2f3efc5e.Funding.

1045 Wesolowski A., Metcalf CJE., Eagle N., Kombich J., Grenfell BT., Bjørnstad ON., Lessler J.,

1046 Tatem AJ., Buckee CO. 2015. Quantifying seasonal population fluxes driving rubella

1047 transmission dynamics using mobile phone data. Proceedings of the National Academy of

$1048 \quad$ Sciences of the United States of America 112: 11114-11119. DOI: 
1050

1051

1052

1053

1054

1055

1056

1057

1058

1059

1060

1061

1062

1063

1064

1065

1066

1067

1068

1069

1070

1071

White PJ., Fox J., Weber J., Fidler S., Ward H. 2014. How Many HIV infections may be averted by targeting primary infection in men who have sex with men? Quantification of changes in transmission-risk behavior, using an individual-based model. The Journal of infectious diseases 210:S594-S599. DOI: 10.1093/infdis/jiu470.

WHO. 2017.Zika situation report. Available at http://www.who.int/emergencies/zikavirus/situation-report/10-march-2017/en/(accessed May 9, 2017).

WHO Ebola Response Team. 2014. Ebola Virus Disease in West Africa - The First 9 Months of the Epidemic and Forward Projections. New England Journal of Medicine 371:14811495. DOI: 10.1056/NEJMoa1411100.

Wiratsudakul A., Paul MC., Bicout DJ., Tiensin T., Triampo W., Chalvet-Monfray K. 2014. Modeling the dynamics of backyard chicken flows in traditional trade networks in Thailand: implications for surveillance and control of avian influenza. Tropical Animal Health and Production 46:845-853. DOI: 10.1007/s11250-014-0575-8.

Wiratsudakul A., Triampo W., Laosiritaworn Y., Modchang C. 2016. A one-year effective reproduction number of the 2014-2015 Ebola outbreaks in the widespread West African countries and quantitative evaluation of air travel restriction measure. Travel Medicine and Infectious Disease 14:481-488. DOI: 10.1016/j.tmaid.2016.06.011.

Xiang B., Gao P., Kang Y., Ren T. 2017. Importation of Zika Virus in China: A significant risk in southern China. Journal of Infection 74:328-330. DOI: 10.1016/j.jinf.2017.01.004.

Ximenes R., Amaku M., Lopez LF., Coutinho FAB., Burattini MN., Greenhalgh D., WilderSmith A., Struchiner CJ., Massad E. 2016. The risk of dengue for non-immune foreign visitors to the 2016 summer olympic games in Rio de Janeiro, Brazil. BMC Infectious 
1072 Diseases 16:186. DOI: 10.1186/s12879-016-1517-z.

1073 Zanluca C., Melo VCA de., Mosimann ALP., Santos GIV dos., Santos CND dos., Luz K.,

1074 Zanluca C., Melo VCA de., Mosimann ALP., Santos GIV dos., Santos CND dos., Luz K.

1075 2015. First report of autochthonous transmission of Zika virus in Brazil. Memórias do

1076 Instituto Oswaldo Cruz 110:569-572. DOI: 10.1590/0074-02760150192.

1077 Zhang Q., Sun K., Chinazzi M., Pastore y Piontti A., Dean NE., Rojas DP., Merler S., Mistry D.,

1078 Poletti P., Rossi L., Bray M., Halloran ME., Longini IM., Vespignani A. 2017. Spread of

1079 Zika virus in the Americas. Proceedings of the National Academy of Sciences:201620161.

$1080 \quad$ DOI: $10.1073 /$ pnas. 1620161114.

1081 Zhong Y Bin., Liu XQ., Deng YC., Xu PH., Zhong GR., Zhang W. 2016. First case of

1082 laboratory-confirmed zika virus infection imported into China. Chinese Medical Journal

1083 129:2013-2014. DOI: 10.4103/0366-6999.187864.

1084 Zinszer K., Morrison K., Brownstein JS., Marinho F., Santos AF., Nsoesie EO. 2017.

1085 Reconstruction of zika virus introduction in Brazil. Emerging Infectious Diseases 23:92-94.

$1086 \quad$ DOI: $10.3201 /$ eid2301.161274.

1087 


\section{Figure 1 (on next page)}

Conceptual frameworks of different epidemic models.

The colors represent epidemiological status: susceptible ( $S$, blue), exposed ( $E$, gray), infectious (I, red), and recovered ( $R$, green). (A) Basic SIR compartmental model. Individuals are assumed to be well-mixed and are classified only according to their epidemiological status. (B) Vector-borne compartmental model. The subscripts $\mathrm{H}$ and $\mathrm{M}$ denote human and mosquito, respectively. Both host and vector individuals are assumed to be well-mixed and are classified only according to their epidemiological status. (C) Spatial model. Individuals are located at different locations. The transmission of infection between an infectious individual and a susceptible individual at distance $x$ may occur with probability $K(x)$. (D) Metapopulation model. The entire population is divided into two distinct subpopulations, each with independent disease transmission dynamics, together with interactions between subpopulations. The subpopulation in each patch is mixed homogeneously. (E) Network model. The model is formed by at least two basic components: vertex and edge. Vertices are connected by edges defined by the relationship of interest such as trade or travel. Infectious diseases are modeled to spread via the edges in this model. (F) Individual-based model. In this most complicated model, the stochastic epidemiological dynamics for each individual can be explicitly simulated with a set of characteristics including epidemiological status, spatial location, interaction preference, behavior traits, etc. 
PeerJ

A. Compartmental model

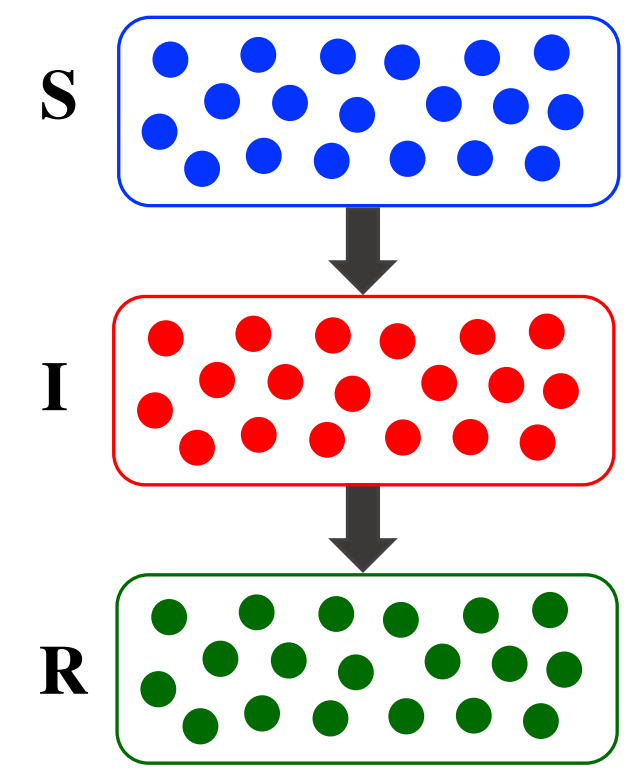

D. Metapopulation model

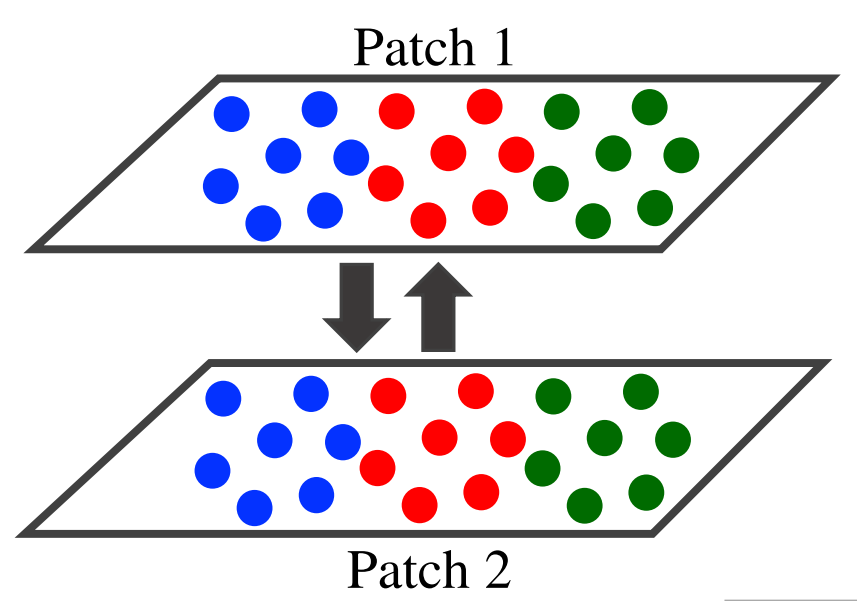

B. Vector-borne

compartmental model

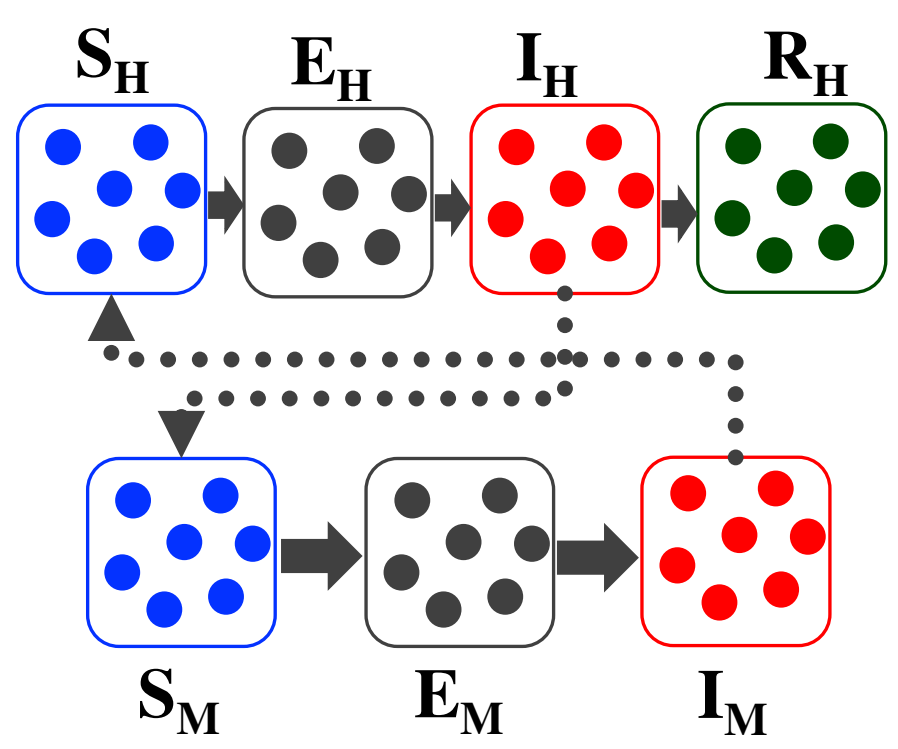

E. Network model

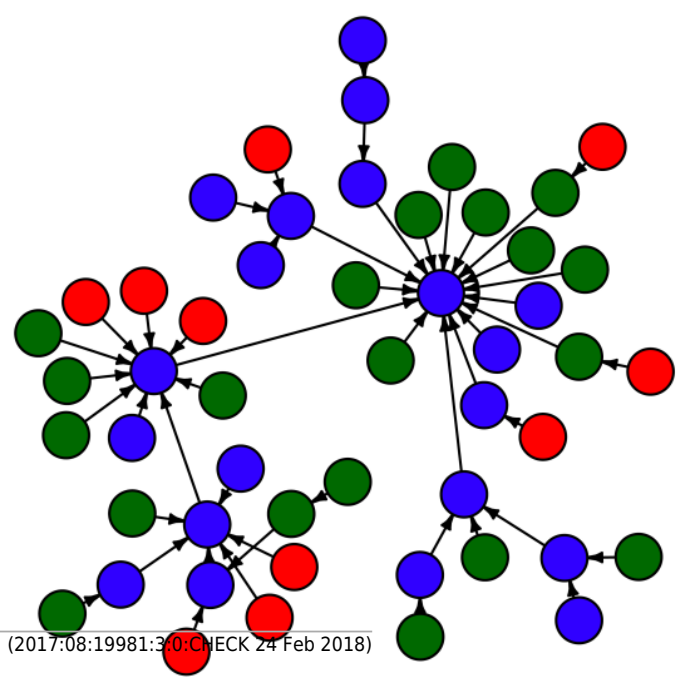

C. Spatial model

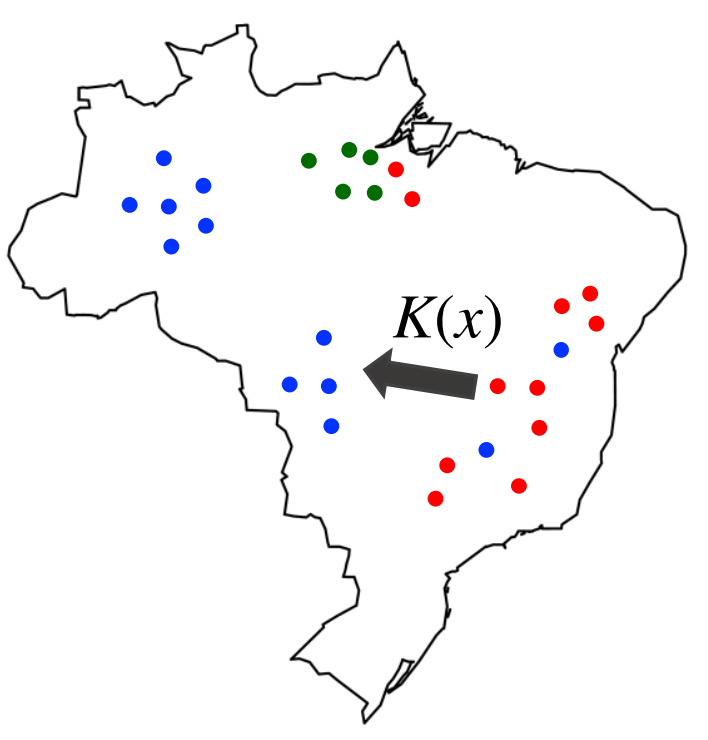

F. Individual-based model

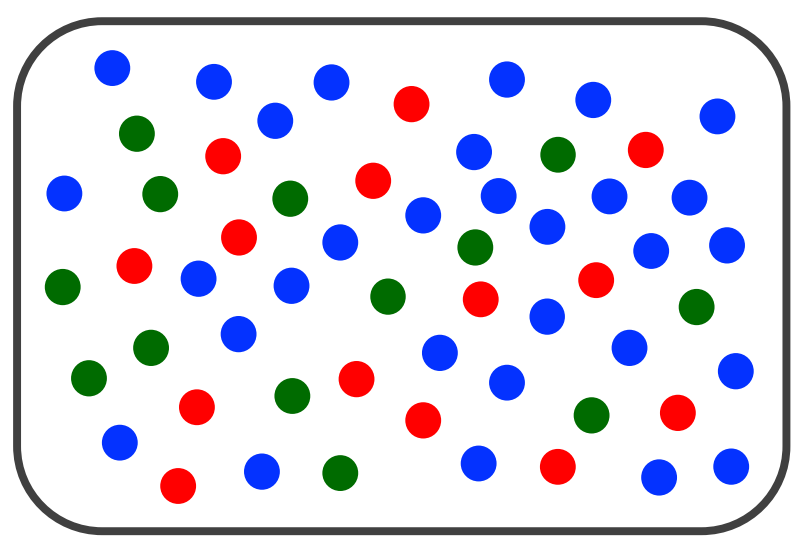




\section{Table $\mathbf{1}$ (on next page)}

Examples of mathematical models used in Zika virus studies, 2007-2017.

Note that a model is marked as "compartmental" only when the population is divided into groups according to only their health status. 
1 Examples of mathematical models used in Zika virus studies, 2007-2017. Note that a model is 2 marked as "compartmental" only when the population is divided into groups according to only 3 their health status.

\begin{tabular}{|c|c|c|c|c|c|c|c|c|}
\hline \multirow[b]{2}{*}{ Period } & \multirow[b]{2}{*}{$\begin{array}{l}\text { Location } \\
\text { (Country/Region/ } \\
\text { Continent) }\end{array}$} & \multirow[b]{2}{*}{$\begin{array}{l}\text { Population } \\
\text { (Compartments) }\end{array}$} & \multicolumn{5}{|c|}{ Model architecture } & \multirow[b]{2}{*}{ References } \\
\hline & & & 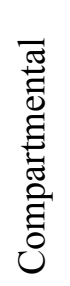 & 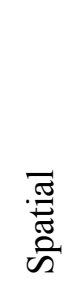 & 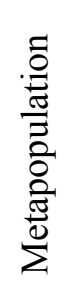 & $\begin{array}{l}\frac{y}{0} \\
\frac{0}{0} \\
z\end{array}$ & 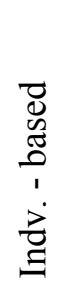 & \\
\hline $2007-2012$ & Micronesia & $\begin{array}{l}\text { Human (SEIR) } \\
\text { Mosquito (SEI) }\end{array}$ & $\mathrm{X}$ & & & & & $\begin{array}{l}\text { Funk et al., } \\
2016\end{array}$ \\
\hline $\begin{array}{l}2007, \\
2013-2014, \\
2014\end{array}$ & $\begin{array}{l}\text { Micronesia, } \\
\text { French Polynesia, } \\
\text { New Caledonia }\end{array}$ & $\begin{array}{l}\text { Human (SEIR) } \\
\text { Mosquito (SEI) }\end{array}$ & $\mathrm{X}$ & & & & & $\begin{array}{l}\text { Champagne } \\
\text { et al., } 2016\end{array}$ \\
\hline 2013-2014 & French Polynesia & $\begin{array}{l}\text { Human (SEIR) } \\
\text { Mosquito (SEI) }\end{array}$ & $\mathrm{X}$ & & & & & $\begin{array}{l}\text { Kucharski } \\
\text { et al., } 2016\end{array}$ \\
\hline 2013-2016 & $\begin{array}{l}\text { French Polynesia, } \\
\text { French West } \\
\text { Indies }\end{array}$ & Human (SIR) & $\mathrm{X}$ & & & & & $\begin{array}{l}\text { Riou et al., } \\
2017\end{array}$ \\
\hline 2014-2017 & $\begin{array}{l}\text { American } \\
\text { continent }\end{array}$ & $\begin{array}{l}\text { Human (SEIR) } \\
\text { Mosquito (SEI) }\end{array}$ & & & $\mathrm{X}$ & & & $\begin{array}{l}\text { Zhang et } \\
\text { al., } 2017\end{array}$ \\
\hline 2015 & $\begin{array}{l}\text { American } \\
\text { continent }\end{array}$ & Human (SIR) & & $\mathrm{X}$ & & & & $\begin{array}{l}\text { Perkins et } \\
\text { al., } 2016\end{array}$ \\
\hline $2015-2016$ & Brazil & $\begin{array}{l}\text { Human (SI) } \\
\text { Mosquito (SI) }\end{array}$ & & $\mathrm{X}$ & & & & $\begin{array}{l}\text { Fitzgibbon } \\
\text { et al., } 2017\end{array}$ \\
\hline $2015-2016$ & Brazil & Human (ND) & & $\mathrm{X}$ & & & & Zinszer et \\
\hline
\end{tabular}




\begin{tabular}{|c|c|c|c|c|c|c|c|c|}
\hline & & & & & & & & al., 2017 \\
\hline 2015-2016 & $\begin{array}{l}\text { Brazil, } \\
\text { Colombia, } \\
\text { El Salvador }\end{array}$ & $\begin{array}{l}\text { Human (SEAIR) } \\
\text { Mosquito (SEI) }\end{array}$ & $\mathrm{X}$ & & & & & $\begin{array}{l}\text { Gao et al., } \\
2016\end{array}$ \\
\hline 2016 & United States & Human (SEIR) & $\mathrm{X}$ & & & & & $\begin{array}{l}\text { Castro et } \\
\text { al., } 2017\end{array}$ \\
\hline 2016 & Brazil & $\begin{array}{l}\text { Human (SEIR) } \\
\text { Mosquito } \\
\text { (SEIR) }\end{array}$ & & & & & $\mathrm{X}$ & $\begin{array}{l}\text { Matheson } \\
\text { et al., } 2017\end{array}$ \\
\hline ND & Brazil & $\begin{array}{l}\text { Non-human } \\
\text { primates (SIR) } \\
\text { Mosquito (SI) }\end{array}$ & $\mathrm{X}$ & & & & & $\begin{array}{l}\text { Althouse et } \\
\text { al., } 2016\end{array}$ \\
\hline ND & Worldwide & $\begin{array}{l}\text { Human (ND) } \\
\text { Mosquito (ND) }\end{array}$ & & $\mathrm{X}$ & & & & $\begin{array}{l}\text { Alaniz, } \\
\text { Bacigalupo } \\
\& \quad \text { Cattan, } \\
2017\end{array}$ \\
\hline ND & ND & $\begin{array}{l}\text { Human } \\
\text { (SIR/SEIR) } \\
\text { Mosquito (SI) }\end{array}$ & $\mathrm{X}$ & & $\mathrm{X}$ & & & $\begin{array}{l}\text { Baca- } \\
\text { Carrasco } \\
\& \\
\text { Velasco- } \\
\text { Hernández } \\
\text {,2016 }\end{array}$ \\
\hline ND & ND & $\begin{array}{l}\text { Human (SIR) } \\
\text { Mosquito (SI) }\end{array}$ & & & $\mathrm{X}$ & $\mathrm{X}$ & & $\begin{array}{l}\text { Saad-Roy } \\
\text { et al., } 2016\end{array}$ \\
\hline
\end{tabular}




\begin{tabular}{|l|l|l|l|l|l|l|l|l|}
\hline ND & ND & $\begin{array}{l}\text { Human } \\
\text { (SIR, } \\
\text { Si }{ }^{p} \text { IR, } \\
\text { UAF })\end{array}$ & & & & & & \\
& & & & & & & \\
\hline
\end{tabular}

4

$5 * \mathrm{ND}=$ Not designated

6 